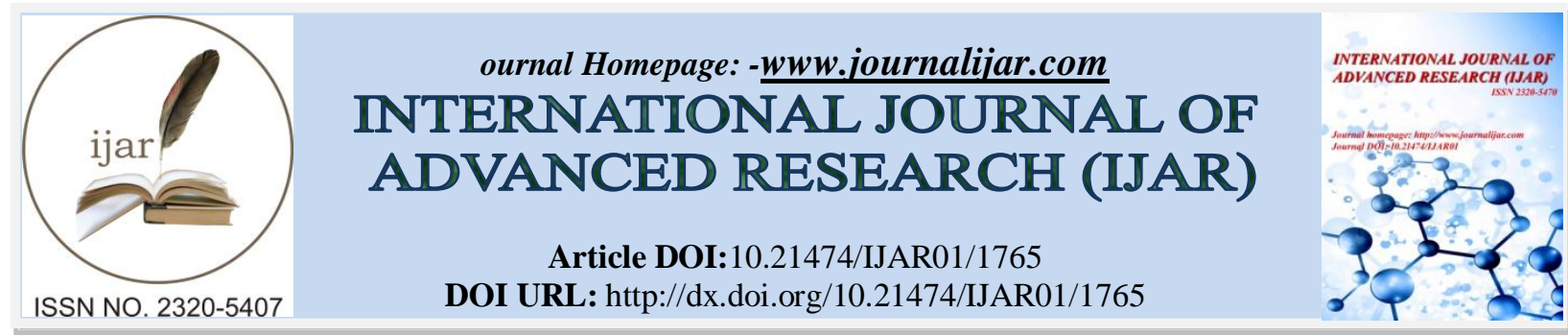

RESEARCH ARTICLE

\title{
SEDIMENTLOGY OF QUATERNARY DEPOSITS OF NARMADA RIFT VALLEY IN INCREASING ANTIQUITY WITH SPECIAL REFERENCETO HOMONID LOCALITY HATHNORA DISTRICT SEHORE MP INDIA.
}

1. Ex. Director, Geological Survey of India.

\author{
Dr. A. A.Khan ${ }^{1,2}$ and Dr. Maria Aziz ${ }^{3}$.
}

2. Director, Rajeev Gandhi Proudyogiki Mahavidyalaya, Bhopal-462042, M.P India.

3. Director, Pri-Med Care, Lewisville Texas 75067 USA.

\section{Manuscript Info}

(..........................

Manuscript History

Received: 12 August 2016

Final Accepted: 13 September 2016

Published: October 2016

\section{Abstract}

In the area around Hatnora in the central sector of Narmada valley Quaternary deposits are confined in trough like basin, in this segment it embraces the quaternary landscape with stepped sequence of Narmada terraces (NT1 to NT3), where Boulder conglomerate is exposed at the base of these deposits. The Boulder conglomerate is persistent horizon and represent distinct fluvial-glacial phase of sedimentation. It is underlian by Boulder bed which is concealed under younger sediments in the valley.The Quaternary landscape embodies imprints of tectonisam which revealed that sedimentation had been controlled by mechanics of SONATA LINEAMENT ZONE. The Quaternary deposits of Narmada valley represent the thickest deposits in faulted and sinking platform under structural riparian rift trench which is undisclosed and remained unrevealed. The work so far carried out is restricted to quaternary deposits of exposed section of $18 \mathrm{~m}$ of river section only, no work has been done on concealed strata of quaternary deposits below th Boulder conglomerate, source of sediments, mode of transportation, deposition tectonic and environment of sedimentation to conceive the model of quaternary sediment. The inadequate data of concealed quaternary strata, environment of sedimentation, their diaposition and correlation in vertical chronology in time and space restricted the systemetic search of human remains with precise strata in synchronization of mechanics of tectonics and sedimentation in rift valley. The records of search of human skull and its remains revealed that the search was mostly random and confined around to hominid locality Hathnora from where skull of Homo erectus was reported by Sonakia (1984) except Sankhyan, A. R. (1997b) no further addition in tracing the human remains and its evolution is made. The present studies on various aspects of sedimentology of exposed section and bore hole logs across the vertical column of about $280 \mathrm{~m}$ in synchronisation of tectonisam and environment sedimentation in vertical chronology in faulted trough may provide clues in understanding the modal of quarternary deposits in rift 
valley and may assist in search of human skull and its remains. In the present study 202 sediment samples were collected from exposed section and bore hole logs across the vertical column of 280 $\mathrm{m}$ to trace environments of sedimentation in Pleistocene to Holocene time. The statistical parameters viz MZ, STD, SKI, and KG of sediment samples were computed of Quaternary blanket of Narmada. The syntesised study of these parameters revealed that the quaternary deposits consists of sediments of three domain viz glacial, fluvioglacial and fluvial representing Boulder bed, Boulder conglomerate and Fluvial deposits of paleo-domain of Narmada (NT1 to NT3). The study of various parameters their binary relation, their concentration of plots cluster and trends and patterns revealed three breaks in sedimenttaion in vertical column at $120 \mathrm{~m}, 210 \mathrm{~m}$ and 280 $\mathrm{m}$ in increasing antiquity from base in Narmada valley.

The binary clusters of plots of mean size and sorting, mean size and skewness, mean size and kurtosis are used in delineating and fencing boundary between the glacial and fluvio glacial and fluvial sediments. The concentration of these plots separates $87 \%$ sediments fluvial domain from fluvio-glacial $94 \%$ of the fluvial-glacial from glacial. The glacial sediments are un-oriented and un-organized,fluvio-glacial moderately organized whereas, the sediments of fluvial domain are well organized are in synchronization to shape size sorting, and display a balance harmony and ecology in conformity of sedimentation Khan et.al (2015) which is also authnticated by heavy mineral assemblage of sediments of quaternary coloumn Khan et.al (2016).

Copy Right, IJAR, 2016,. All rights reserved.

\section{Introduction:-}

The Narmada river originates from the Amarkantak plateau of Satpura Ranges in Rewa at an elevation of about $1057 \mathrm{~m}\left(22040^{\prime}-810\right.$ 45') flows westerly course for about $1300 \mathrm{kms}$ length across the middle of Indian subcontinent before entering Gulf of Cambay in the Arabian sea near Bhrouch in Gujarat state. It enters the alluvial plain and passes through the gorge of about $19 \mathrm{kms}$ long consisting of Marble rocks near Jabalpur. The river course of Narmada conspicuously straight and is controlled by ENE_WSW to E_W lineament, is bounded by Vindhyan in the north and Satpura in the south. The valley has maximum width of about $32 \mathrm{kms}$.

The Narmada basin covers an area of about 12950 sq. km starting from west of Jabalpur $\left(23^{0} 07^{0} 790530\right)$ to Harda $\left(22^{0} 29^{\prime} ; 76^{0} 58^{\prime}\right)$ to Bharouch in Gujarat state for a distance of about $1300 \mathrm{~km}$. It is found to be ideal locus of Quaternary sedimentation in Central India as witness by multi-cyclic sequence of Quaternary terraces in the valley. The general elevation of Narmada alluvial plain varies between 265.7 and $274.3 \mathrm{~m}$ above the sea level. The gradient of this plain in this stretch is about $1 \mathrm{~m} / \mathrm{Km}$ towards West. (Plate No -1)

The Hathnora is located about $10 \mathrm{kms}$ from Hoshangaba in up stream of Narmada; it is approchable by all weather roads. It has received attention of scientist after the recovery of Human Skull Sonakia (1984).The Quaternary deposits of the Narmada valley represent the thickest quaternary deposits in peninsular India. It contain the richest vertebrate fossil assemblage including only known Hominid fossil from the Indian sub-continent (Sonakia 1984) The boulder bed which yielded Hominid fossil from boulder conglomerate reported to be of fluvio-glacial origin for first time ( Khan \& Sonakia 1992). Beside occurrences of ash beds with fossileferous boulder conglomerate (Khan \& Rahate 1991) Achariya (1993) indicates volcanic source. It appears that close to the completion of cycle of deposition of the boulder bed there was vilolent volcanic eruption in around Middle to uperPleistocen time which was subsequently settled down across the globe and in the pennisular India during the quaternary sedimentation. The occurrences of association of two marked horizons at different levels further revealed the cyclic eruption and settling of volcanic matrix was occurred with a pause during sedimentation. Khan et.al. (1991). Khan and Sonakia (1992) reported for the first time glacial and interglacial deposit in the Narmada valley, Central India which is represented 
by arid and humid cycles. The lithostratigraphy of Narmada valley described by Khan (1984), Khan \&Benarjee (1984), Khan \&Rahate (1990-91), Khan \&Sonakia (1992), Khan et al (1991), Rahate \& Khan (1985), Khan (1991), Khan \& Sonakia (1992), Yadav\& Khan (1996). (Plate No -2)

The Quaternary lithostratigraphy and sedimentological aspects were studied and in the Narmada valley (Khan 1984, Khan \&Benarjee 1984, Khan \& Rahate 1990-91-90 Khan \&Sonakia 1992, Khan \&et al 1991, Rahate\& Khan 1985, Khan et al. 1991, Khan 1991, Khan et al. 1992, Yadav\& Khan 1996. The Narmada valley embodied complete sequence of Quaternary deposits from lower Pleistocene to Holocene (Khan \& Sonakia (1992). Khan, et.al (1912), Khan (2012) et.al Khan ( in press), Khan ( in press).The results of sedimentological studies Khan ( 2015), quartz grain morphology, Khan ( 2014), quartz grain morphology,Palesole Quaternary column section in Hominid locality in central sector of Narmada revealed the presence of complete sequence of quaternary sediments in Narmada rock basin viz glacial, fluvio-glacial and fluvial domain whereas the boulder conglomerate which has yielded human skull is of fluvio-glacial origin from Khan \&Sonakia (1991)

The Quartz grain morphology of sediment column Khan (2014) Quartz grain morphology of different paleo- sole, , Khan (2014), Ash bed Khan \& Maria (2012) Khan \& Maria (1912) Heavy mineral assemblage Khan ( 2016) tephra stratigraphy, Khan et.al (1991 )Acharya, S.K. and Basu, P.K. (1993) Khan etal (2014) Khan et.al.(2015) Ash fall and its impects ( 2015 ) Khan (2016) magnetostratigraphy, and bio-stratigraphy and correlation of sediment columns intra valley wise, inter valley wise and on unified Quaternary Platform Khan et.al (2012) focusing on hominid localities of China have been studied on quaternary platform which have given new insight on the age of the Narmada Homo erectus.

The Narmada valley forms an ENE-WSW lineament and Quaternary deposits in it are confined to trough like basin in Peninsular India with digonestic morphogenetic and morphotectonic manifestation it a tectonic significance.

The Quaternary deposits of the Narmada valley represent the thickest Quaternary deposits in peninsular India which were deposited in a tectonic trench of SONATA LINEAMENT ZONE., the sedimentation has been controlled and synchronised by mechnisam of tectonisam during entire span of sedimentation from Lower Pleistocene to Holocene time. The association of fossils and stone implements with Quaternary deposits of Narmada are well described, quarries on various aspects on geology geomorphology, sedimentolgy, provenance of sediments, stream kinetics, stratigraphy, chronology ,tectonics, neotectonic, subsurface geometry, and overall model of Quaternary sedimentation of Narmada in faulted and oscillating rift trench remained silent undisclosed and unrevealed hidden misteries needed attention.In the present studies an attempt has been made for the first time to conduct detailed sedimentlogical studies at Hathnora and around on the merits of exposure of quaternary deposits in river sections, scarp section $(18 \mathrm{~m})$ and bore hole $\operatorname{logs}$, sediment samples have been collected precisely of entire quaternary coloumn in central sector of Narmada from base to the surface in increasing antiquity. In area around Hathnora four sections of sampling were selected with an objective to build- up and conceive the Quaternary sedimentological model of sedimentation of the Hominid locality Hathnora from where human skull was recovered by Sonakia (1984) in Narmada valley. About 280 sediment sample were collected from surface and subsurface quaternary deposits and from ongoing drilling project logs up to $180 \mathrm{~m}$ below the ground surface and carried out detailed statistical analysis in the laboratory which is presented in this paper. (Plate No QST-4, 5,6,\& 7)

\section{The Statistical Computations:-}

The statistical analysis of sediment sample of the area around Hathnora Narmada valley was carried out particle size distribution curves were expressed on a $\Phi$ scale. Folk and Ward's (1957) graphical method was adopted to calculate mean size $(\mathrm{Mz})$, sorting $(\sigma \mathrm{I})$, Skewness $(\mathrm{SKI})$ and Kurtosis $(\mathrm{KG})$. This method involves the measurement of several percentiles from cumulative curves $(\Phi 5, \Phi 16, \Phi 25, \Phi 50, \Phi 75, \Phi 84$ and $\Phi 95)$. The formulae are as follows: 


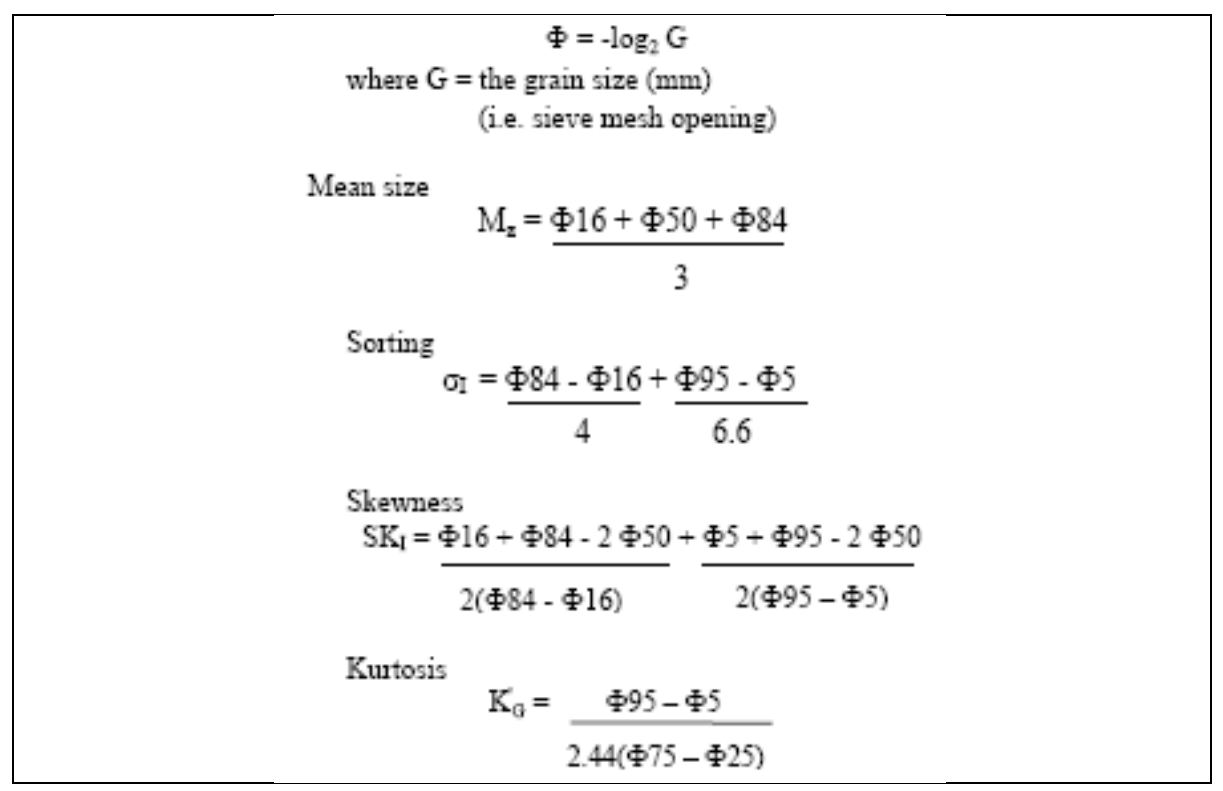

The computed textural parameters of sediments and their binary relation applied as tool in differentiating the various environments of Quaternary sedimentation are incorporated in (Plate QST-4 to 7), the same keys are used to analyze and differentiate sediments of various domains in vertical quaternary coloumn in Narmada valley.

\section{Hathnora Section_I:-}

$\left(22^{\circ} 52^{\prime \prime} \mathrm{N} ; 77^{\circ} 52^{\prime \prime} \mathrm{E}\right)$

Statistical Parameters of Quaternary Deposits Of Narmada Valley Plate No QST-4

In Hathnora section -I

\begin{tabular}{|c|c|c|c|c|c|c|c|c|c|c|c|c|}
\hline Terrace and its & \multicolumn{3}{|c|}{ mean size } & \multicolumn{3}{|c|}{ standard deviation } & \multicolumn{3}{|c|}{ skewness } & \multicolumn{3}{|c|}{ kurtosis } \\
\hline & ave & & & ave & ran & & ave & $\mathrm{ral}$ & & ave & $\mathrm{rar}$ & \\
\hline NT1 & $\begin{array}{r}2.15 \\
5\end{array}$ & $\begin{array}{r}1.62 \\
8\end{array}$ & $\begin{array}{r}3.24 \\
8\end{array}$ & $\begin{array}{r}0.29 \\
5\end{array}$ & 0.268 & $\begin{array}{r}0.39 \\
5\end{array}$ & 2.15 & $\begin{array}{r}0.77 \\
5\end{array}$ & $\begin{array}{r}0.42 \\
5\end{array}$ & $\begin{array}{r}0.19 \\
5\end{array}$ & 0.238 & $\begin{array}{r}0.32 \\
9\end{array}$ \\
\hline NT2 & $\begin{array}{r}1.62 \\
5\end{array}$ & $\begin{array}{r}-42 \\
0.4\end{array}$ & $\begin{array}{r}2.29 \\
6\end{array}$ & $\begin{array}{r}1.62 \\
5\end{array}$ & 0.233 & $\begin{array}{r}0.39 \\
6\end{array}$ & & & & $\begin{array}{r}0.32 \\
5\end{array}$ & 0.263 & $\begin{array}{r}0.53 \\
9\end{array}$ \\
\hline NT3 & $\begin{array}{r}1.15 \\
5\end{array}$ & $\begin{array}{r}0.62 \\
5\end{array}$ & $\begin{array}{r}1.75 \\
3\end{array}$ & $\begin{array}{r}0.32 \\
8\end{array}$ & $\begin{array}{r}0.038 \\
9\end{array}$ & $\begin{array}{r}0.16 \\
5\end{array}$ & -0.21 & $\begin{array}{r}- \\
0.41 \\
5\end{array}$ & $\begin{array}{r}0.32 \\
5\end{array}$ & $\begin{array}{r}0.61 \\
9\end{array}$ & 0.754 & $\begin{array}{r}0.88 \\
6\end{array}$ \\
\hline $\mathrm{BC}$ & $\begin{array}{r}1.22 \\
8\end{array}$ & -2.58 & 2.55 & $\begin{array}{r}1.75 \\
5\end{array}$ & 1.002 & 3.42 & & & & 1.22 & $\begin{array}{r}0.872 \\
1\end{array}$ & $\begin{array}{r}2.11 \\
2\end{array}$ \\
\hline BB & 2.5 & -0.87 & 3.45 & 2.35 & 1.42 & $\begin{array}{r}3.87 \\
5\end{array}$ & $\begin{array}{r}- \\
0.25 \\
8\end{array}$ & $\begin{array}{r}- \\
0.41 \\
5\end{array}$ & 2.2 & 0.98 & 0.6 & 1.85 \\
\hline
\end{tabular}

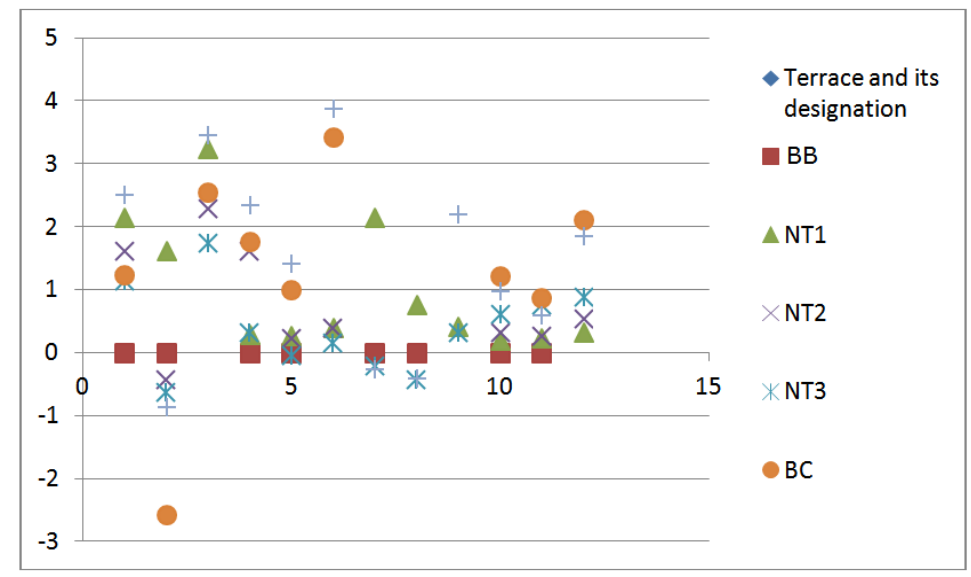


The Hathnora Section _I is located at village Hathnora from where the sediment samples have been collected from the exposed section of Quateranery deposits of about $18 \mathrm{~m}$ scrap and from Boulder conglomerate exposed at base with section exposed about 5m.and fluvial terraces where their section are exposed in river section and scarp deposited in increasing antiquity. The Boulder conglomertae and Boulder bed are not fully exposed in the section; hence samples have been collected from on goinging bore hole logs below the surface of $280 \mathrm{~m}$ in increasing antiquity. Table No QST-4

\section{Boulder bed:- \\ (Glacial Deposits) \\ Mean Size (MZ)}

The average mean size (MZ) of glacial sediments collected from bore holes around Hathnora, Shahganj, and Hoshangabad at the depth of about 100 of $180 \mathrm{~m}$ below the surface is $2.50 \emptyset$ (Find sand). It ranges from $-0.87 \varnothing$ to $3.45 \varnothing$ i.e. the sediments consist of coarse to fine sand with silt and clay. The mean size of sediments exhibit heterogeneous association and show significant variation from bottom to top in increasing antiquity and stratigraphic column .The erratic behavior of size matrix and sudden rise in mean size at level of $70 \mathrm{~m}$ below the surface is conspicuous features of these deposits. The size distribution of sediment strata concealed under the wedge of boulder conglomerate is irractic and anisotroic in contrast to overlying sediments perhaps due to different environment of sedimentation controlled co-ordiated by high and fluctuating energy condition of sedimentation. The sediments seem to be derived from mixed sources by dragging and traction in an unorganised system of transportation on unstable platform.

Inclusive Graphic Standard Deviation (ð):-

The average standard deviation is $2.35 \emptyset$ (very poorly sorted). It varies from $1.42 . \varnothing$ to $3.875 \varnothing$ i.e. the sediments are poorly sorted to extremely poorly sorted. The majority of the sample shows the range of standard deviation of order ranging from $2.00 \emptyset$ to $3.355 \emptyset$. Out of 50 samples $60 \%$ of sample display very poor sorting, $15 \%$ moderate sorting and $20 \%$ extremely poor sorting. The sediments display no significant improvement in sorting in vertical column between 30 to $70 \mathrm{~m}$ below the surface. The variation in sorting appears to have been related with mean size which is irratic and anisotropic, in addtion to diversiy it is affected by lateral mixing of sediments in valley at various points.

\section{Inclusive Graphic Skewness (SKI):-}

The average skewness is $-0.258 \varnothing$ (very negative skewed). It ranges from $-0.425 \varnothing$ to $02.20 \varnothing$, which revealed that the sediments are very negative to positive skewed, $20 \%$ samples are symmetrical $15 \%$ positive skewed $45 \%$ negative skewed $15 \%$ nearly symmetrical and 5\% very positive skewed. The 55\% samples in middle column of Quaternary strata between 30 to $70 \mathrm{~m}$ below the surface are coarse skewed and $45 \%$ fine skewed. The sediments exhibit erratic values of skewness in sediments column between 30 to $120 \mathrm{~m}$ at depth below the surface. The sediments are assorted and as a whole show strong variation in departure towards coarseness as well as with fineness. The departure from symmetry appears to be related with deviation of mean size. In general the asymmetry passes from middle to upper segment are coarse skewed to fine skewed, which suggest constant variation in energy condition of the transporting system during sedimentation.

\section{Graphic Kurtosis (KG):-}

The average value of Kurtosis (KG) is $0.98 \varnothing$ (Mesokurtic). It ranges from 0.60 to $1.85 \emptyset$ (very platykurtic to very leptokurtic). The $6 \%$ samples are very leptokurtic, 50\% mesokurtic, $21 \%$ leptokurtic, $23 \%$ are platykurtic. The $68 \%$ of samples in the lower strata below $150 \mathrm{~m}$ at depth is mesokurtic where as in the middle segment of Quaternary strata between 75-150 $\mathrm{m} \mathrm{40 \%} \mathrm{are} \mathrm{meokurtic} \mathrm{where} \mathrm{as} \mathrm{in} \mathrm{the} \mathrm{upper} \mathrm{sediments} \mathrm{column} \mathrm{between} 30$ to $120 \mathrm{~m}$ at depth below the surface $26 \%$ sample are meokurtic. The relative values of kurtosis in relation to the depth and configuration of the basin suggests non static and oscillating platform of sedimentation in central part of valley related to the tectonics and consequential change in the energy condition of the system.

\section{Fluvio- glacial Sediments:- (Boulder conglomerate):- Mean Size (MZ):-}

The average mean size (MZ) is $1.228 . \varnothing$, it ranges from $-2.580 \varnothing$ to $2.55 \varnothing$ i.e the sediments consist of very coarse sand to fine silt and clay. The maximum value $-2.580 \varnothing$ is noticed between 15 to $40 \mathrm{~m}$ below ground level along the exposed wedge of Boulder conglomerate in river section. As whole sediments are assorted and size of sediment is 
erratic and irregular. The mean size shows significant decrease in selected levels in the concealed sediment below the ground level beyond $40 \mathrm{~m}$ depth. The further down it mean size significant decline with strong fluctuation, appears to be due to strong lateral making of sediments brought by the streams resulted consequent upon the meeting of glacier at various points in the valley Renick of Singh (1980).

\section{Inclusive Graphic Standard Deviation:-}

The average standard deviation is $1.755 \varnothing$ (poorly sorted). It ranges from $1.002 \varnothing$ to $3.421 . \varnothing$ The $54 \%$ of samples are poorly sorted and rest $44 \%$ very poorly sorted. The $94 \%$ of the samples show the sorting beyond $1.300 \varnothing$, i.e. the majority of sediments are poorly sorted to very poorly sorted. The sediments show strong fluctuation in the sorting but exhibit no significant improvement up ward. The sediments considered to be deposited by glacial out wash from glacial front Eyles (1979).

\section{Inclusive Graphic Skewness (SKI):-}

The average skewness value is $-0.21 \varnothing 8$ (very negative skewed). The skewness of fluvio-glacial sediments varies from -0.415 to $+0.325 \varnothing$ i.e. sediments are strongly coarse to fine skewed. The $24 \%$ of the samples are negative to very negative skewed, $30 \%$ negative skewed, $30 \%$ nearly symmetrical, $15 \%$ positive skewed and $1 \%$ are very positive skewed. The skewness value of these sediments indicates the diverse and heterogeneous association of the sediments ranging in size from fine and to gravel. The skewness shows sharp increase in its value upward in the bore hole sediment data section with local variation strongly suggest decline in energy condition of transporting agency in the valley.

\section{Graphic Kurtosis (KG):-}

The average kurtosis is $1.220 \varnothing$ (very leptokurtic). It varies from 0.8721 to $2.112 \varnothing$. The $3 \%$ samples are platykurtic, $10 \%$ mesokurtic, $34 \%$ are leptokurtic, and $53 \%$ are very leptokurtic. The sediments were poorly sorted in the central part of size distribution curve than the tails. In the stretch of vertical section of sampling and data command of bore hole assuming the local variation the kurtosis does not show steady decrease in its value upward and the local variation seems to be due to local mixing of sediments brought by the flash streams resulted due to melting of glacier repeatedly in the valley.

\section{Fluvial deposits:- \\ (Sediments of paleo domain of Narmada):- Mean Size (MZ):-}

The average value of mean size of terrace deposit NT-1 is $2.155 \varnothing$ (fine sand) and it ranges from $1.628 \varnothing$ to $3.248 \varnothing$ (medium to fine sand), average value of mean size of terrace NT-2 (NT-2A, NT-2B, NT-2C). is $1.625 \varnothing$ (medium sand) and it ranges between $-0.425 \varnothing$ to $2.296 \varnothing$ (very coarse sand to fine sand). The average value of mean size of terrace NT-3 is The average value of mean size of terrace is $1.155 \varnothing$ (medium sand) and ranges from $-0.625 \varnothing$ to $1.753 \varnothing$ (medium sand to very fine sand).

The average and range and mean size revealed that the sediments of older terraces NT-2 (NT-2A, NT-2B, and NT2C). and NT-3 consist of very coarse to very fine sand where as younger terrace NT-1 (NT-2A, NT-2B) and NT2 predominantly consist of medium to fine sand, except with very little variation, the mean size of sediments progressively decreased in decreasing antiquity of terraces which appears to be related with repeated reworking of sediments, steady decrease in load carrying capacity of channel towards the latter stages of sedimentation. The variation in mean size suggests the fluctuation in energy condition of channel related with cilmatic changes in the watershed area.

\section{Inclusive Graphic Standard Deviation:-}

The average value of standard deviation for the sediments of NT-1 is $0.295 \varnothing$ (very well sorted) and it ranges from 0.268 to $0.395 \varnothing$ (well sorted to very well sorted), average value of sorting for the sediments of terrace NT-2 (NT$2 \mathrm{~A}, \mathrm{NT}-2 \mathrm{~B}, \mathrm{NT}-2 \mathrm{C}$ ) is $1.625 \varnothing$ (moderately sorted) and it ranges from 0.233 to $0.396 \varnothing$ (well sorted to very well sorted), average value for the sediments of terrace NT3 is 0.376 (well sorted) and it ranges from 0.281 to $0.438 \varnothing$ (well sorted to very well sorted). The average and relative range values of standard deviation indicate that the sediments of older terraces NT3 are (moderately sorted to well sorted) NT2 (NT-2A, NT-2B, NT-2C), (well sorted to very well sorted) and NT1 well sorted to very well sorted and NTO are very well sorted. The sediments show progressive improvement in sorting from older terraces to younger terraces appears to be related with the mean size and energy condition of the channel, which constantly decrease towards the later phases of sedimentation. The size 
distribution curve reveals more than one population of sediments whereas the probability plot reveal that the terraces NT-1 to NT3 average consist of 57\% and 43\% traction and suspension 1oad respectively. The traction load decreases in decreasing antiquity of terraces in the valley.

\section{Inclusive Graphic Skewness (SKI):-}

The Skewness (SKI) average value of for terrace NT-1 is $+2.25 \varnothing$ (positive skewed). It ranges from $-0.775 \varnothing$ to $0.425 \varnothing$ (very negative skewed to very positive skewed). Average value of skewness for terrace NT-2 (NT-2A, NT$2 \mathrm{~B}, \mathrm{NT}-2 \mathrm{C}$ ) is $+0.1 .65 \varnothing$ (positive skewed), it ranges from -0.592 to $0.232 \varnothing$ (very negative skewed to positive skewed). Average value for terrace NT-3 is +0.328 (very positive skewed), it ranges from $-0.0389 \varnothing+0.568 \varnothing$ (very negative skewed to very positive skewed). The sediments of terrace NT-1 is (strongly negative skewed) where as the sediments NT2 to NT-3 are progressively positively skewed. The negative skewness is resultant of high energy condition whereas the positive skewness indicates low energy. The average and relative range values of skewness from NT-1 to NT-3 indicate there is decrease in energy condition of channel towards the late history of sedimentation.

\section{Inclusive Graphic Kurtosis (KG):-}

The Kurtosis (KG) average value of for terrace NT-1 is $0.195 \varnothing$ (very platykurtic) , it varies from 0.238 to $0.329 \varnothing$ (platykurtic). Where as average value for NT-2 (NT2-A, NT2-B, NT2-C) is $0.325 \varnothing$ (very platykurtic) and ranges from 0.263 to $0.539 \varnothing$ (very platykurtic). Average value for terrace NT3 is 0.619 (very platykurtic) and varies from 0.754 to $0.886 \varnothing$ (platykurtic to very platykurtic).

The sediments of NT3 are platykurtic to very platykurtic and NT-1 to NT3 in nature. The average value of Kurtosis decreases upwards which indicate a normal peakedness of sediments as well strong concentration of grains about median diameter. The relatively lower value of NT-1 indicates that most of the sediments the source of sediments have were derived from close proximity and nearest provenances. Plate No QST-4

\section{HathnoraSection II:-}

$\left(22{ }^{\circ}\right.$ 52" N; $77^{\circ} 58$ " E)

Statistical Parameters of Quaternary Deposits of Narmada Valley Plate No QST-5

In Hathnora section -II

\begin{tabular}{|l|r|r|r|r|r|r|r|r|r|r|r|r|}
\hline $\begin{array}{l}\text { Terrace and its } \\
\text { designation }\end{array}$ & \multicolumn{3}{|c|}{ mean size } & \multicolumn{3}{c|}{ standard deviation } & \multicolumn{3}{c|}{ skewness } & \multicolumn{3}{c|}{ kurtosis } \\
\hline & ave & \multicolumn{2}{|c|}{ range } & \multicolumn{1}{|c|}{ ave } & \multicolumn{1}{c|}{ range } & ave & range & ave & \multicolumn{2}{c|}{ range } \\
\hline NT1 & 1.75 & 6.75 & 3.2 & 0.29 & 0.19 & 0.35 & 0.213 & - & 0.296 & 1.64 & 1.52 & 1.99 \\
& & 5 & & 5 & 5 & & & 0.125 & & 6 & & \\
\hline NT2 & 2.39 & 0.25 & 0.35 & 1.25 & 0.15 & 1.96 & - & -0.39 & - & 1.41 & 0.82 & 2.48 \\
& & 5 & 5 & & 6 & & 0.155 & & 0.135 & 5 & & \\
\hline NT3 & 3.42 & 6.33 & 3.75 & 1.59 & 1.45 & 2.05 & - & -0.38 & 0.129 & 1.12 & 0.67 & 1.42 \\
& 2 & & & 6 & & & 0.116 & & & & 9 & 9 \\
\hline BC & 0.49 & -0.5 & 1.75 & 1.69 & 0.53 & 2.18 & - & - & 0.33 & 1.22 & 0.88 & 1.75 \\
& 5 & & 5 & 9 & & & 0.196 & 0.366 & & 5 & 5 & 2 \\
\hline BB & 0.65 & - & 3.35 & 2.82 & 2.39 & 3.26 & - & - & 2.25 & 2.35 & 0.86 & 3.1 \\
& & 0.77 & 5 & & 4 & 2 & 0.238 & 0.355 & & & & \\
\hline
\end{tabular}

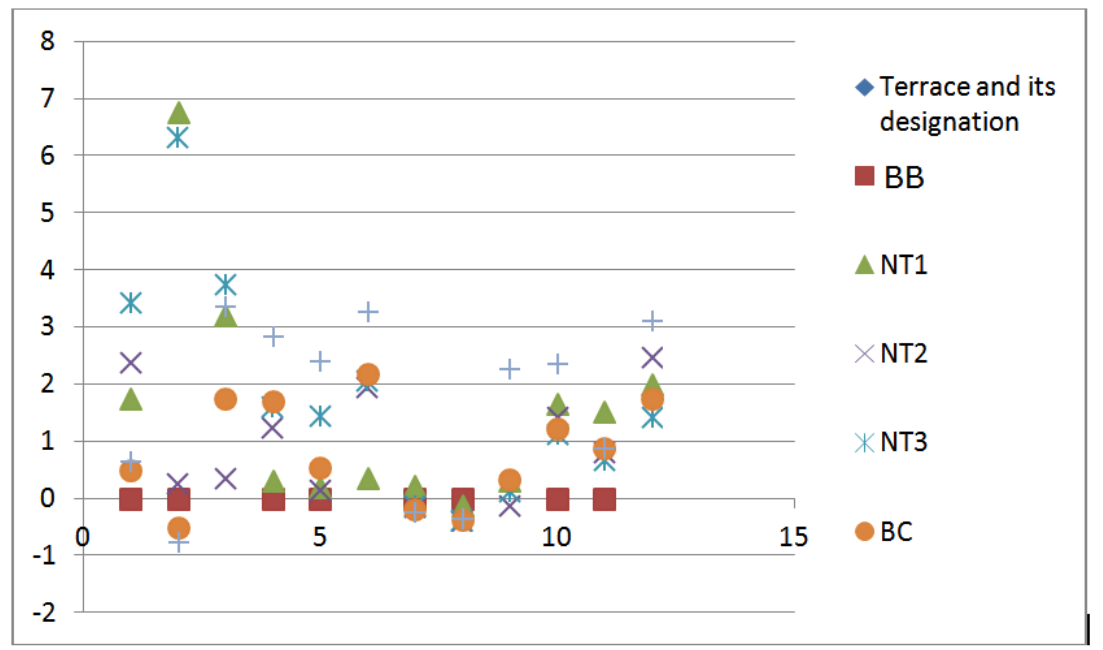


The Hathnora Section_II is located in between villages Hathnora-Nathankheri-Sardarpur in upstream of Hathnora, sediment samples have been collected from exposed section of $16 \mathrm{~m}$ as well as from on going drilling between the depths of 95 to $190 \mathrm{~m}$ below the surface.The Boulder conglomerate is partly exposed in river section and Boulder bed concealled under the younger deposits. Table No QST-5

\section{( Glacial Deposits):-}

Mean Size ( MZ):-

The average mean size (MZ) of sediments of boulder bed is 0.650 which represent the sediments between the depth of about 105 to $150 \mathrm{~m}$ below the surface around Hathnora, Shahganj, and Hoshangabad.It varies from -0.770 to $3.355 \varnothing$ i.e. the sediments consist of coarse to fine sand with silt and clay. The (MZ) of these sediments exhibit heterogeneous association and display significant variation from bottom to top in increasing antiquity and stratigraphic coloumn.The erratic behaviour of mean size and anomolous rise in decresing antiquity revealed asymmetric and un organised sedimentation perhaps due to tectonics instability of sediementation platform.

\section{Inclusive Graphic Standard Deviation (ð):-}

The average standard deviation (ð) of sediemtsis $2.82 \varnothing$ (very poorly sorted) where as it varies from $1.42 . \varnothing$ to $3.875 \varnothing$ i.e. the sediments are (poorly sorted to extremely poorly sorted). The majority of the sample shows the range of standard deviation of order ranging from 2.399 to $3.262 \varnothing$, among these $65 \%$ of sample show poor sorting, $15 \%$ very poor sorting and $20 \%$ extremely poor sorting. There is no significant improvement in sorting in sediments column between 30 to $120 \mathrm{~m}$ below the surface. The variation in sorting appears to have been related with mean size, which is greatly affected by lateral mixing of sediments in valley and unstability of platform of sedimentation.

\section{Inclusive Graphic Skewness (SKI):-}

The average skewness (SKI) of sediments is $-0.238 \varnothing$ (very negative skewed). Where as it ranges from -0.335 to $2.25 \varnothing$ which Indicate that sediments are (very negative to positive skewed), 10\% samples symmetrical $15 \%$ positive skewed $45 \%$ negative skewed $15 \%$ nearly symmetrical $5 \%$ positive skewed and $10 \%$ very positive skewed. The 55\% samples in middle column of Quaternary strata between 75-150 m below the surface are coarse skewed and $45 \%$ fine skewed. The sediments exhibit variation in values of skewness in sediments column between 30 to $120 \mathrm{~m}$ at depth below the surface The sediments are assorted and as a whole show strong variation in departure towards coarseness as well as with fineness. The departure from symmetry appears to be related with deviation of mean size. In general the asymmetry passes from middle to upper segment are coarse skewed to fine skewed, which suggest constant variation in energy condition of the transporting system perhaps due to climatic changes during sedimentation.

\section{Graphic Kurtosis (KG):-}

The average value of Kurtosis (KG) is $2.35 \varnothing$ (Masokurtic). It ranges from 0.860 to $3.10 \varnothing$ (very platy kurtic to very laptokurtic). The $6 \%$ samples are very leptokutic, $50 \%$ mesokurtic, $21 \%$ leptokurtic, $23 \%$ are platykurtic. The $68 \%$ of samples in the lower strata of quaternary deposits at depth of about $150 \mathrm{~m}$ below the surface is mesokurtic where as in the middle segment of Quaternary deposits between $75-150 \mathrm{~m} \mathrm{40 \%}$ are meokurtic where as in the upper sediments column between 30 to $120 \mathrm{~m}$ at depth below the surface about $26 \%$ sample are meokurtic. The relative values of kurtosis in relation to the depth and configuration of the basin suggests oscillating platform of sedimentation in central part of valley related to the tectonic pulsation supplemented by change of climate and related in the energy condition of the system.

\section{Fluvio-Glacial Deposits:- (Boulder conglomerate):- Mean Size (MZ):-}

The average mean size (MZ) is $0.495 \varnothing$. It ranges from -0.500 to $1.755 \varnothing$ i.e the sediments consist of very coarse sand to fine silt and clay. The maximum value $-2.580 \varnothing$ is noticed in between depth of 15 to $40 \mathrm{~m}$ below ground level along the exposed wedge of Boulder conglomerate in river section. As whole sediments are asorted and size of sediment is irratic and anamolous. The (MZ) shows signigicant decrease in size from in the consealed sediment below the ground level byond $40 \mathrm{~m}$ depth. The further down it shows significant decline in the size but with strong fluctuation, appears to be due to strong lateral mixing of sediments brought by the streams resulted consequent upon the melting of glacier at various points in the valley Renick of singh (1980). 


\section{Inclusive Graphic Standard Deviation (ð):-}

The average standard deviation (ð) is $1.699 \varnothing$ (poorly sorted). It ranges from 0.530 to2.180 Ø. The statistical analysis of sediment revealed that $54 \%$ of samples are poorly sorted and rest $44 \%$ very poorly sorted. The $94 \%$ of the samples show the sorting beyond $1.302 \varnothing$. i.e. the majority of sediments are poorly sorted to very poorly sorted. The sediments show strong fluctuation in the sorting index but exhibit no any significant improvement upward. The sdiments considered to be deposited by glacial out wash from glacial front Eyles (1979).

\section{Inclusive Graphic Skewness (SKI):-}

The average skewness (SKI) value is $-0.196 \varnothing$ (very negative skewed). The skewness of fluvio-glacial sediments varies from -0.366 to $0.330 \varnothing$-i.e. sediments are strongly coarse to fine skewed. The $24 \%$ of the samples are (negative to very negative skewed), 30\% negative skewed, 30\% nearly symmetrical, 15\% positive skewed and $1 \%$ are very positive skewed. The skewness value of these sediments indicates diverse and heterogeneous association of the sediments ranging in size from fine and to gravel. The (SKI) shows sharp increase in its value upward in the bore hole sediment section with local variation stongly suggest decline in energy condition of transporting agency in the valley to wards later phases of sedimentation.

\section{Graphic Kurtosis (KG):-}

The average kurtosis (KG) is $1.225 \varnothing$ (very leptokurtic). It varies from 0.885 to $1.752 \varnothing$.The statistical anlysis revealed that $11 \%$ samples are platykurtic, $10 \%$ mesokurtic, $24 \%$ are leptokurtic, and $55 \%$ are very leptokurtic. The sediments were poorly soted in the central part of size distribution curve than the tails. In the stratch of vertical section of about $26 \mathrm{~m}$ below the ground surface. The kurtosis does not show stready decrease in its value upward and the local variation seems to be due to local mixing of sediments brought by the flash and flushing streams resulted due to climatic changes.

\section{Fluvial Deposits:-}

Mean Size (MZ):-

The average value of mean size of sediments of paleo domain of Narmada of NT-1 is $1.750 \varnothing$ (fine sand) and it ranges from 6.755 to $3.200 \varnothing$ (medium to fine sand), average value of mean size of terrace NT-2 (NT-2A, NT-2B, NT-2C) is $2.390 \varnothing$ (medium sand) and it ranges between -0.425 to 2.296 (very coarse sand to fine sand) where as average value of mean size of terrace NT-3 is average value of mean size is $3.422 \varnothing$ (medium sand) and ranges from 0.255 to $0.355 \varnothing$ (medium sand to very fine sand).

The average and relative values of mean size revealed that the sediments of older terraces NT-2(NT-2A, NT-2B, NT-2C). and NT-3 consist of very coarse to very fine sand where as younger terrace NT-1 (NT-2A, NT-2B) and NT2 predominantly medium to fine sand, except with little variation, the mean size of sediments progressively decreased in decreasing antiquity of terraces which appears to be repeated working of sediments in valley. The variation in mean size suggests the fluctuation in energy condition of channel system due to climatic changes.

\section{Inclusive Graphic Standard Deviation (ð):-}

The average value of standard deviation for the sediments of NT-1 is $0.275 \varnothing$ (very well sorted) where as it varies from 0.195 to $0.350 \varnothing$ (well sorted to very well sorted). The Narmada terrace NT-2 (NT-2A, NT-2B, NT-2C) show average value $1.250 \varnothing$ (moderately sorted) and it varies from 0.156 to $1.960 \varnothing$ well sorted to very well sorted.The older terrace of Narmada indictes average value 0.376 well sorted and it ranges from 1.450 to $2.050 \varnothing$ (well sorted to very well sorted). The study of stanadrd deviation and its average and relative values of indicate that the sediments of older terrace NT3 average value is $1.596 \varnothing$ where as it varies from 1.430 to $2.052 \varnothing$ moderately sorted to well sorted NT2 (NT-2A, NT-2B, NT-2C) well sorted to very well sorted and NT1 well sorted to very well sorted and NT0 are very well sorted. The sediments show progressive improvement in sorting from older terraces to younger terraces appears to be related with the mean size and energy condition of the channel, which constantly declines towards the later phases of sedimentation. The size distribution curve reveals more than one population of sediments whereas the probability plot reveal that the terraces NT-1 to NT3 average consist of 57\% and $43 \%$ traction and suspension load respectively. The traction load decreases in decreasing antiquity of terraces in the valley.

\section{Inclusive Graphic Skewness (SKI):-}

The average value of (SKI) for terrace NT-1 is $0.213 \varnothing$ (positive skewed). It ranges from0.125 to $0.296 \varnothing$ (very negative skewed to very positive skewed), average value of skewness for terrace NT-2 (NT-2A, NT-2B, NT-2C). is 
$+-0.155 \varnothing$ (positive skewed), it ranges from -0.592 to 0.232 (very negative skewed to positive skewed). Average value for terrace NT-3 is +-0.116 (very positive skewed), it ranges from 0.380 to $0.129 \varnothing$ (very negative skewed to very positive skewed). The sediments of terrace NT-1 is strongly negative skewed where as the sediments NT2 to NT-3 are progressively positively skewed. The negative skewness is resultant of high energy condition whereas the positive skewness indicates low energy. The average and relative range values of skewness from NT-1 to NT-3 indicate the decrease in energy condition of channel towards the late history of sedimentation.

\section{Inclusive Graphic Kurtosis (KG):-}

Average value of Kurtosis (KG) for terrace NT-1 is $1.646 \varnothing$ (very platykurtic) it ranges from1.520 to $1.990 \varnothing$ (platykurtic). Average value for NT-2 (NT2-A, NT2-B, NT2-C) is $1.415 \varnothing$ (very platykurtic) and ranges from 0.263 to 0.539 (very platykurtic). Average value for terrace NT3 is $1.120 \varnothing$ (very platykurtic) and varies from 0.679 to $1.429 \varnothing$ (platykurtic to very platykurtic). The sediments of NT3 are platykurtic to very platykurtic and NT-1 to NT3 are very platykurtic in nature. The average value of Kurlosis decreases upwards which indicate a normal peakednes $\mathrm{s}$ of sediments as well strong concentration of grains about median diameter. The relatively lower value of NT-1 indicates that most of the sediments were derived from close proximity and nearest provenances. (Plate No QST-5)

HathnoraSectionIII:-

$\left(22^{\circ} 52^{\prime \prime} \mathrm{N} ; 77^{\circ} 45^{\prime \prime} \mathrm{E}\right)$

Statistical Parameters of Quaternary Deposits Of Narmada Valley Plate No QST-6 In Hathnora section -III

\begin{tabular}{|c|c|c|c|c|c|c|c|c|c|c|c|c|}
\hline Terrace and its & \multicolumn{3}{|c|}{ mean size } & \multicolumn{3}{|c|}{ standard deviation } & \multicolumn{3}{|c|}{ skewness } & \multicolumn{3}{|c|}{ kurtosis } \\
\hline & & & & ave & ran & & ave & & & ave & & \\
\hline NT1 & $\begin{array}{r}0.092 \\
3\end{array}$ & $\begin{array}{r}- \\
2.65 \\
1\end{array}$ & $\begin{array}{r}3.24 \\
8\end{array}$ & 3.34 & 2.62 & 4.30 & $\begin{array}{r}-\overline{-} \\
0.064\end{array}$ & 0.52 & 0.425 & $\begin{array}{r}0.71 \\
6\end{array}$ & $\begin{array}{r}0.49 \\
0\end{array}$ & $\begin{array}{r}1.10 \\
0\end{array}$ \\
\hline NT2 & 1.625 & $\begin{array}{r}- \\
0.42 \\
5\end{array}$ & $\begin{array}{r}2.29 \\
6\end{array}$ & $\begin{array}{r}1.62 \\
5\end{array}$ & 0.233 & $\begin{array}{r}0.39 \\
6\end{array}$ & $\begin{array}{l}- \\
0.155\end{array}$ & $\overline{0}-\overline{390}$ & $\overline{0}-230$ & $\begin{array}{r}0.32 \\
5\end{array}$ & $\begin{array}{r}0.26 \\
3\end{array}$ & $\begin{array}{r}0.53 \\
9\end{array}$ \\
\hline NT3 & 1.155 & $\begin{array}{r}- \\
0.62 \\
5\end{array}$ & $\begin{array}{r}1.75 \\
3\end{array}$ & $\begin{array}{r}0.32 \\
8\end{array}$ & $\begin{array}{r}- \\
0.038 \\
9\end{array}$ & $\begin{array}{r}0.16 \\
5\end{array}$ & $0.210^{-}$ & - & 0.325 & $\begin{array}{r}0.61 \\
9\end{array}$ & $\begin{array}{r}0.75 \\
4\end{array}$ & $\begin{array}{r}0.88 \\
6\end{array}$ \\
\hline $\mathrm{BC}$ & 1.032 & $\begin{array}{r}- \\
2.53 \\
0\end{array}$ & $\begin{array}{r}3.12 \\
0\end{array}$ & $\begin{array}{r}1.56 \\
3\end{array}$ & 0.950 & $\begin{array}{r}2.50 \\
0\end{array}$ & $\overline{0}-\mathbf{0 7 8}$ & $\begin{array}{l}- \\
0.480\end{array}$ & $\begin{array}{l}0.97 \\
1\end{array}$ & $\begin{array}{r}1.31 \\
6\end{array}$ & $\begin{array}{r}0.47 \\
6\end{array}$ & $\begin{array}{r}1.52 \\
0\end{array}$ \\
\hline BB & 0.655 & -0.77 & $\begin{array}{r}3.35 \\
5\end{array}$ & 2.82 & 2.399 & $\begin{array}{r}3.26 \\
2\end{array}$ & 0.238 & 0.335 & 2.25 & 2.35 & 0.86 & $\begin{array}{r}3.10 \\
0\end{array}$ \\
\hline
\end{tabular}

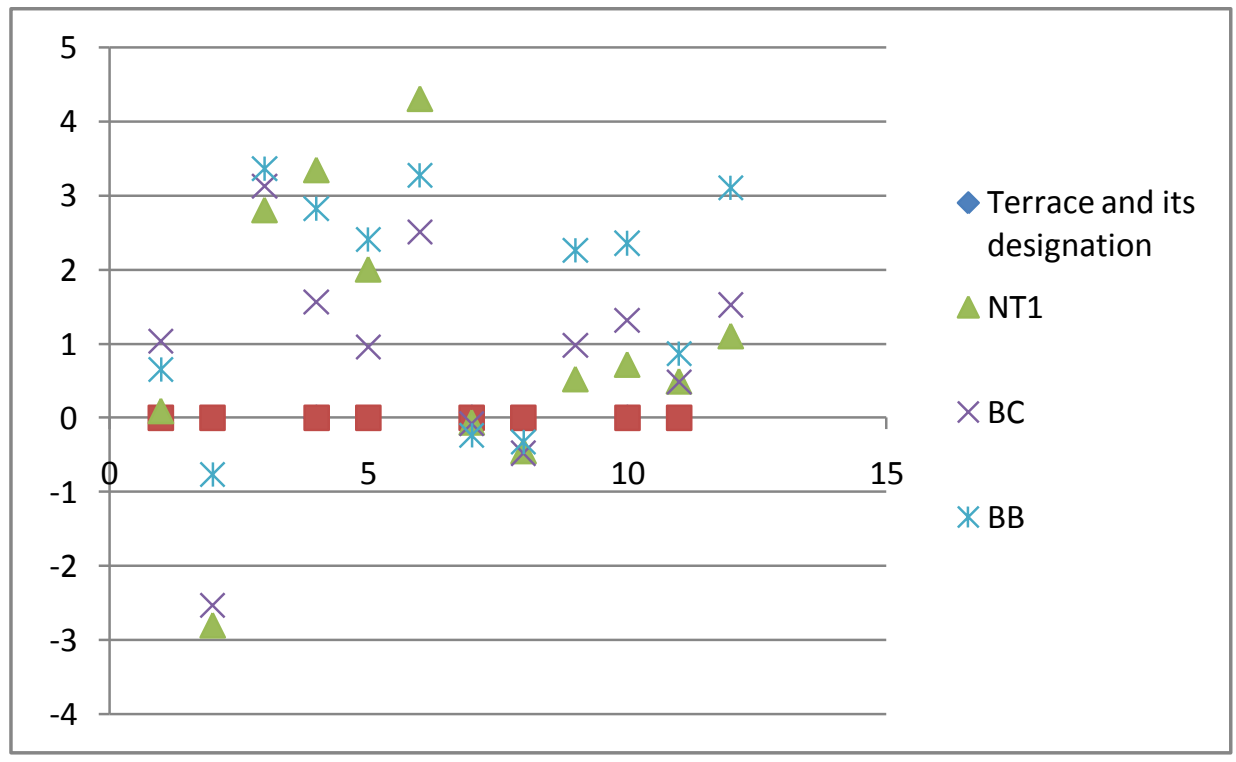


The Hathnora Section_III is located at between village Hathnora-Shahganj in down stream of Homonid locality, in this section sediment samples collectively have been taken from exposed section of about $16 \mathrm{~m}$ and from on going bore hole log of conealled sediments of Boulder bed and Boulder conglomerate between the depth of 93 to $195 \mathrm{~m}$ below the surface in increasing antiquity. Table No QST-6

\section{Boulder bed:- \\ (Glacial Deposit):- \\ Mean Size (MZ):-}

The average mean size (MZ) of Boulder bed and associated sediments is $0.09 \varnothing$ (coarse sand), it varies from $-2.81 \varnothing$ to $2.8 \varnothing$ i.e. the sediments consist of very coarse to fine sand. The maximum value of (MZ) is -2.81 about $80 \mathrm{~m}$ below surface and minimum 2.8 near the outer limit of boulder bed around Hathnora\& Hoshangabad. The (MZ) shows sharp decrease in size to ward up ward of ground surface from the basement. It shows decrease in its value but with strong fluctuations, which is attributed to the mixing of sediments brought by the sub-glacier activities. It is seen that the mean size constantly decreases with size fluctuations in between the level of 15 to $50 \mathrm{~m}$ form base of deposits in rock basin. The mean size thereafter display there is a sharp rise in size of sediment persistently up ward increases in size of sediments and its variation in these deposits indicate the irratic anisotropic sdimentation on un even platfrom where the transportation of sediments from the source occurred by traction and in close and tight and narrow platform. Khan et.al (1990) Khan et.al (2015) Khan et.al (2016)

\section{Inclusive Graphic Standard Deviation (ð):-}

It is a measure of sorting which reflects the consistence in the energy level of depositing medium. In respect sediments of boulder bed the average standard deviation is $3.34 \varnothing$ (very poorly sorted). It varies from $2.00 \varnothing$ to 4.30 $\varnothing$ i.e. the sediments are poorly sorted to extremely poorly sorted. The relative variation and average distribution indicate that $20 \%$ of sample is poorly sorted, 58 very poorly sorted and $22 \%$ are extremely poorly sorted. The sediments however, show slight improvement in sorting upward from the basement. As a whole the sediments of these deposits are extremely assorted and heterogeneous in nature

\section{Inclusive Graphic Skewness (SKI):-}

It denotes the symmetry of grain size frequency distribution. The symmetry curves posses zero value, these with excess fine material show positive value with these excessive coarse material have negative value. The average (SKI) for sediments of boulder bed is $-0.064 \varnothing$ i.e. the sediments are negative skewed. It ranges from $-0.45 \varnothing$ to $+0.52 \varnothing$ i.e. the sediment are negative skewed to positive skewed, which indicate the tendency of gradual decrease in value of (SKI) in upward direction as result of retreat of glacier activities and decrease in the transport capacity. The 56\% of the sample shows the negative value and $44 \%$ positive value. The sediments up to the level of $15 \mathrm{~m}$ from rock basin are very positive skewed to very negative skewed which seems to be due to mixing of sediments brought by cumulative glacial fluvial activities. The sediments show the strong tendency to be positive skewed.

\section{Graphic Kurtosis (KG):-}

It indicates the peakedness of curve lower value of $(\mathrm{KG})$ (platykurtic) points towards broad peak, while value of (KG) (leptokurtic) denotes pronounced peak in the centre. The value of (KG) in the sediments of concealed deposit is highly variable. The average value is $0.716 \varnothing$ (platykurtic); whereas it varies from 0.49 to $1.10 \varnothing$ (very platykurtic to leptokurtic) the average value suggest the fluctuation in the energy condition of the glacier and most intense assorting in the sediments prevailed during the deposition. Inspite of strong variation in (KG) in the vicinity there is tendency in increase in $(\mathrm{KG})$ value towards downward of sequence.

\section{Boulder Conglomerate:- (Fluvio glacial Deposit):- Mean Size (MZ):-}

The average mean size (MZ) of sediments of boulder conglomerate is $1.032 \varnothing$ (medium sand). It varies from $-2.53 \emptyset$ to $3.12 \varnothing$ i.e. the sediments consist of very coarse to very fine sand. The size distribution of these deposits in the study area is extremely irregular and erratic out of 50 samples $10 \%$ of sample show range of mean size of order of $0.75-0.50,21,0.25$ to $0.75, \varnothing 25 \%, 0.75$ to $1.75,35,1.75$ to $2.50 \varnothing$ and $90 \%$ beyond 2.50 . The sediments close to the under lying Boulder bed the down sequence ranges is 0.75 to $0.50 \varnothing$ i.e. coarse to very coarse sand which constantly show decrease in mean size. The sediments in the vicinity of Hathnora at level of $20 \mathrm{~m}$ show range of order of 1.25 to 2.75 with local variation. The sudden rise in mean size are of order 0.50 to 0.15 , indicates the 
intensive mixing of sediments had taken place by the sediments brought by stream resulting from the retreating of glacier at different point on platform of sedimentation in the valley.

\section{Inclusive Graphic Standard Deviation (ð):-}

The standard deviation of sediments of boulder conglomerate varies from 0.95 to $2.50 \varnothing$ i.e. the sediments are poorly sorted to very poorly sorted. The average standard deviation is 1.563 (extremely poorly sorted). Out of 50 samples $8 \%$ are moderately sorted, $10 \%$ poorly sorted and $82 \%$ are very poorly sorted. The sediments near the source are conspicuously exhibit poor sorting and display significant improvement down the stream with local variation. As a whole the sediments are poorly sorted to very poorly sorted and heterogonous in nature sand are typically of fluvio glacial origin.

\section{Inclusive Graphic Skeness (SKI):-}

The average value of skewness (SKI) is $0.078 \varnothing$ i.e. the sediments are fine skewed. It varies from $-0.48+0.97 \varnothing$ i.e. the sediments are skewed very negative skewed very positive. Out of 50 samples $56 \%$ are skewed very positively, $15 \%$ skewed positive and $29 \%$ are skewed very negative. The average and relative value of sediments and their symmetry suggest the heterogeneous association of the sediments ranging from fine sand to gravel size. The skewness generaly increase in increasing antiquity with occasional variation. It is perhaps due to repeated reworking of the sediments up ward to wards younger deposits.

\section{Graphic Kurtosis (KG):-}

The average KG is 1.316 (leptokurtic). It ranges from $476 \varnothing$ to $1.52 \varnothing$ platykurtic to very leptokurtic among these $75 \%$ of the sample fall in very platykurtic class mesokurtic $45 \%$ leptokurtic. The assemblages of these classes of kurtosis suggest the dominance of coarse sediments (Folk 1957). Most of the samples show the Kurtosis value between $0.90-1.20$ except in the area around Hoshangabad where the sedimentation is perhaps affected by lateral mixing brought by the rejuvenated stream under high kinetic channel system in very unorganised organised sediment load from close source.

\section{Fluvial Deposit:-}

\section{(Sediments of Paleo-domain of Narmada):-} MEAN SIZE (MZ):-

The average mean size (MZ) for the sediments of fluvial terraces of Narmada NT1 to NT3 is $2.458 \varnothing$. The maximum value of (MZ) is $-0.491 \varnothing$ is noticed near Shahganj while minimum $4.545 \varnothing$ at Hoshangabad near the confluence of Narmada of Tawa. The (MZ) shows the significant consistency in its value which corresponds to the gentle slope of the river bed down the stream. The mean size sharply decreases in increasing antiquity of sediment sequence.The significant increase in mean size in NT2 (NT2-A, NT2-B, NT2-C) may be due to reactivation of energy of channel system of transporting agency.

Inclusive Graphic Standard Deviation (ð):-

The average standard deviation (ð) for sediment of fluvial terrces is 0.691 (moderately sorted) and it ranges from 0.15 to 1.52 i.e. the sediments are very well sorted to poorly sorted from NT1 to NT3. The rise variation in and around ShahganjHoshangabad section down stream appears to be due to mixing of sediments brought by local tributaries. The sharp improvement in sorting is noticed around Hoshangabad seems to be related with the repeated reworking of sediments and slope element. The sudden decline in sorting co-efficientis resulted either to the nontransport of larger grain down current or due to loss of bed slope of Narmada in this segment of valley. The significant increase in sorting in down current of Hoshngabad indicates repeated reworking of sediments perhaps due to re-activation of channel related due climatic changes.

\section{Inclusive Graphic Skewness (SKI):-}

The average skewness (SKI) of fluvial sediments is 0.0281 , it varies from -0.99 to 0.99 i.e. the sediments are course to fine skewed. It exhibits tendency of gradual increase in value down stream with local variation. This suggests relative increase of fine grain sediment down the stream. The samples upstream of Hoshangabad are negative skewed perhaps due to mixing of sediments of fluvio glacial origin.

Inclusive Graphic Kurtosis (KG):-

The kurtosis (KG) average value is 1.264 that sediments are (Leptokurtic) whereas it varies from 0.72 to 1.72 (Platykurtic to very leptokurtic). The average value suggests the fluctuation in the energy condition of the channel 
system. The mean value of Kurtosis revealed more intensive sorting of central part of size distribution curve than the tails. There is strong tendency in increase of kurtosis value to younger sediments.( Plate No QST-6).

\section{HathnoraSection IV:-}

$\left(22{ }^{\circ}\right.$ 52" $\left.\mathrm{N} ; 77^{\circ} 40 " \mathrm{E}\right)$

Statistical Parameters of Quaternary Deposits of Narmada Valley Plate No QST-7

Hathnora section -IV

Geological

Formation

Geomorphic surface
Mean size Standard deviation

(MZ)

Average Range
(SD)
Skewness
Kurtosis

(SKI)
(KG)

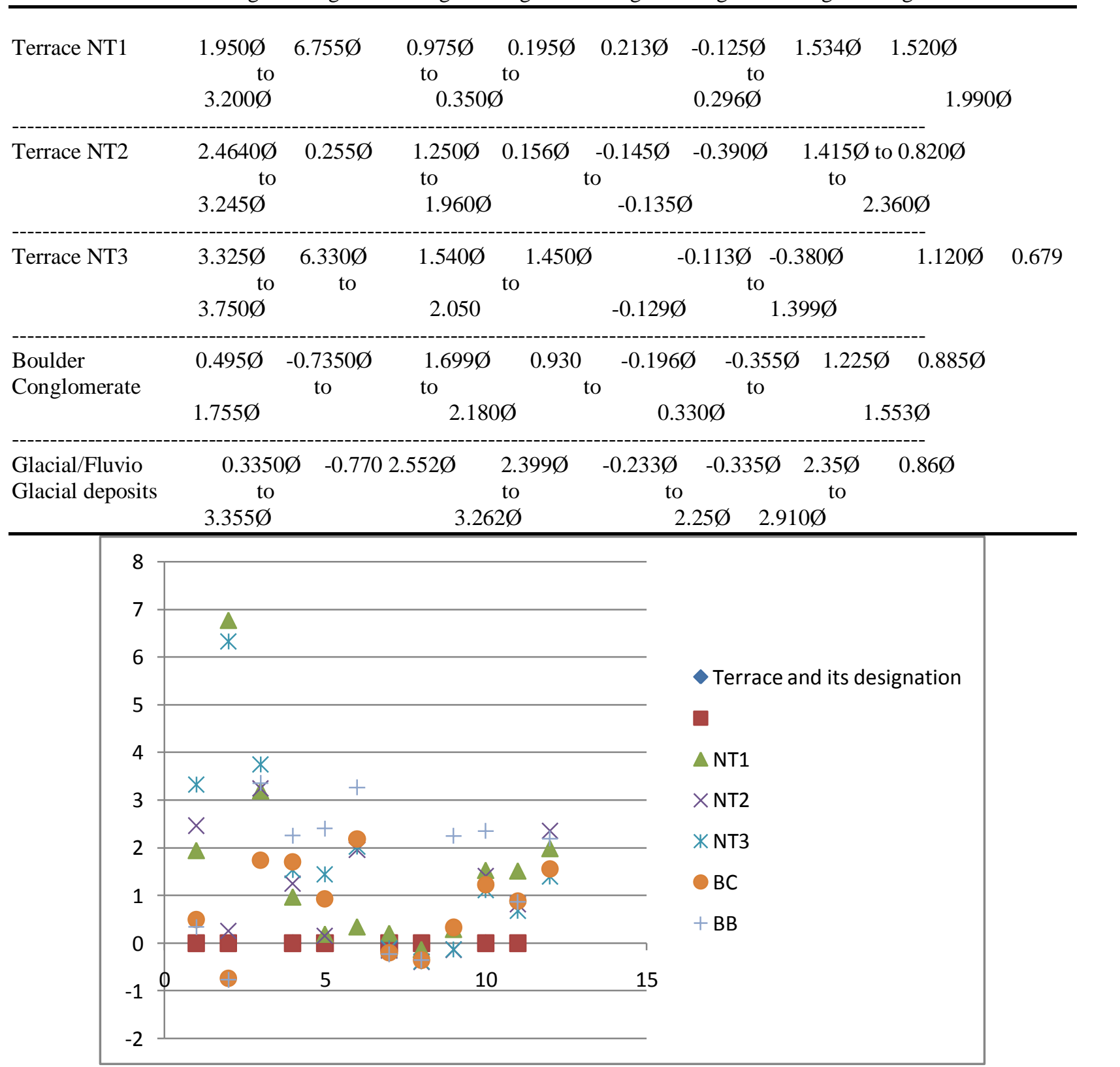

The Hathnora Section _IV is located at between villages Hathnora-Shahganj-Hoshangabad section in down stream of Hominid locality, the samples are collected from exposed section of Quateranery deposits. In river section about 20 $\mathrm{m}$ scrap of sediments of Boulder conglomerate and fluvial terraces are exposed in increasing antiquity. The Boulder 
bed is concealled under younger deposits to estabish the continuity chronology in sequence of in coloumn samples of concealled deposits of Boulder bed and Boulder conglomerate have been collected from gonging bore hole drilling logs between the depths of 80 to $170 \mathrm{~m}$ below the surface. Table No QST-7

\section{Boulder bed:- \\ (Glacial deposit):- \\ Mean Size (MZ):-}

The average mean size of Boulder bed and associated sediments is $0.335 \varnothing$ (very coarse to very fine sand), it varies from $2.815 \varnothing$ to $3.35 \varnothing$ i.e. the sediments consist of very coarse to fine sand. The maximum value of (MZ) is -2.815 $\varnothing$ at the depth of about $80 \mathrm{~m}$ below surface and minimum $2.88 \varnothing$ near the outer limit of boulder bed in Hathnora\&Sahhganj section. The (MZ) shows sharp decrease in size in increasing anitquityto wards younger deposits from the basement. It is seem that the mean size constantly decreases due to cyclic reworking of sediments in valley. The sediments of bore hole log show fluctuations in mean size the (MZ) between the level in between 23 50 form base of quaternary deposits below the surface, there after there is a sharp rise in size of sediment persistently. Increases in size of sediments and its variation in these deposits indicate the extensive mixing of sediment brought by glacier activity in Narmada valley. Khan et.al (2015) Khan et.al (2016)

\section{Inclusive Graphic Standard Deviation (ð):-}

It is a measure of sorting which reflects the consistence in the energy level of depositing medium. In respect to sediments of boulder bed the average standard deviation is $2.55 \varnothing$ (very poorly sorted). It varies from $2.399 \varnothing$ to $3.262 \varnothing$ i.e. the sediments are poorly sorted to extremely poorly sorted. The relative variation and average distribution of standard deviation suggest that $24 \%$ of samples are poorly sorted, $53 \%$ very poorly sorted and $23 \%$ are extremely poorly sorted. The sediments however, show slight improvement in sorting upward from the basement. As a whole the sediments of these deposits are extremely assorted and heterogeneous in nature and typical of glacial environment.

\section{Inclusive Graphic Skewness (SKI):-}

It denotes the symmetry of grain size frequency distribution. The symmetry curves posses zero value, these with excess fine material show positive value with these excessive coarse material have negative value. The average (SKI) of sediments of Boulder bed $-0.335 \varnothing$ that the sediments are negative skewed. It ranges from $-2.35 \varnothing$ to $+2.25 \varnothing$ i.e. the sediment are negative skewed to positive skewed, which revealed the gradual decrease in value of skewness in upward sequence as result of retreat of glacier activities and decrease in the transport capacity. The $56 \%$ of the sample shows the negative value and $44 \%$ positive value. The sediments up to the level of $11032 \mathrm{~m}$ below the surface, these sediments are very positive skewed to very negative skewed which seems to be due to mixing of sediments brought by cumulative glacial fluvial activities. The sediments show the strong tendency to be positive skewed.The statistical analysis of plots of parameters their binary relation and trend of plots are indicate hapazrds and diverse sediment in size symmetry and sorting, the sediment load appers to have transported by bed laod and traction on uneven surface and dump in asymmetric and an isotropic configuration in close system. The sediments and its heavy mineral assemblage have the imprints of tectonics and dynamics of sedimentation Khan et.al (2016) which revealed unstability of platform of sedimentation.

\section{Graphic Kurtosis (KG):-}

It indicates the peakedness of curve lower value of $(\mathrm{KG})$ (platykurtic) points towards broad peak, while value of kurtosis (leptokurtic) denotes pronounced peak in the centre. The value of sediments of concealed deposit is highly variable. The average value is $2.35 \varnothing$ (laptokurtic); whereas it varies from $0.86 \varnothing$ to $2.25 \varnothing$ (very platykurtic to leptokurtic), the average value suggests the fluctuation in the energy condition of the transporting system. The statistical analysis of plots of parameters and their binary relation and correlation at various levels of bore hole samples between 90 to $110 \mathrm{~m}$ below the surface revealed hetrogenous and diverse assemblage of sediments. These sediments hapazardly oriented with diverse size symmetry and sorting index, the sediment load appers to had transported from source by bed load by traction on turmoile platform of sedimentation. The configuration of sediment load was highly asymmetric and provided the close and tight system of sedimentation in intial stages The sediment bear imprints of tectonics and dynamics of sedimentation which further revealed cyclic dislocation and block displacement of site of sedimentation Khan et.al (2016). 


\section{Boulder Conglomerate:- (Fluvio- glacial Deposit):- Mean Size (MZ):-}

The average means size (MZ) of sediments of Boulder conglomerate is $-0.735 \varnothing$ (very coarse sand). It varies from $1.699 \varnothing$ to $1.755 \varnothing$ i.e. the sediments consist of very coarse to very fine sand silt and clay. The size distribution of these deposits in the study area is extremely irregular and erratic out of 52 samples $18 \%$ of sample show range of mean size of order of $0.732 \varnothing-0.55 \varnothing 0.23 \varnothing .-21.00,0.27 \varnothing$ to $0.73 \varnothing 25 \%, 0.75 \varnothing$ to $1.75 \varnothing,, 1.75 \varnothing$ to $2.50 \varnothing$ and $20 . \%$ beyond $2.50 \varnothing$ The sediments close to the under lying Boulder bed the down the sequence ranges $0.75 \varnothing$ to $0.50 \emptyset$ i.e. th sediments are very coarse to very coarse sand which constantly show decrease in size. The sediments in the vicinity of Hathnora along at level of $20 \mathrm{~m}$ below the surface display range of order of $1.55 \varnothing$ to $2.75 \varnothing$ with local variations. The sudden rise in mean size of sediments of are of order $0.50 \varnothing$ to $0.16 \varnothing$ which indicates the intensive mixing of sediments brought by flash stream resulting from glacier front at different point in the valley. The sudden anomalous variation in in mean size may be presumed to the adding of a large bulk of sediments perhaps brought by sub-glacier resulted due to melting of glacial and climatic changes.

Inclusive Graphic Standard Deviation (ð):-

The average value of standard deviation (d) of sediments of boulder conglomerate is $0.930 \varnothing$, i.e the sediments are extremely poorly sorted, it varies from- $0.196 \varnothing$ to $2.180 \varnothing$ i.e. the sediments are poorly sorted to very poorly sorted.The statistical analysis of plots, correlation of different parameters indicate that out of 50 samples $10 \%$ are moderately sorted, $14 \%$ poorly sorted and $76 \%$ are very poorly sorted. The sediments near the source are conspicuously exhibit poor sorting and show and local variation. As a whole the sediments are poorly sorted to very poorly sorted are anisotropic and heterogonous in nature.The sediments display improvement in sorting in increasing antiquity towards younger deposits revealing repeated reworking of sediments from the outer rim of dump sediments by stream resulting due to change of climatic changes.

\section{Inclusive Graphic Skeness (SKI):-}

The average of (SKI) is $-0.355 \varnothing$ i.e. the sediments are fine skewed whereas skewness ranging from $-0.48+0.97 \varnothing$ which further revealed that the sediments are skewed very negative skewed very positive. The statistical analysis of plots of parameters their binary relation and indicate that out of 50 samples 56\% are very skewed positively, 22\% skewed positive and $22 \%$ are skewed very negative. The assemblage of sediments display variable skewness suggests the heterogeneous association of the sediments ranging from fine sand to gravel size. The skewness in general increase with increasing antiquity in lithostratigraphic sequence with occasional variation it is perhaps due to repeated reworking of sediments in same domain from glacial front.

\section{Graphic Kurtosis (KG):-}

The average (KG) is $1.225 \varnothing$ where as it ranges from $0.885 \varnothing$ to $0.330 \varnothing$. Out of 50 sample $42 \%$ of the sample fall in very platykurtic $52 \%$ Mesokurtic $6 \%$ leptokurtic category. The configuration of plots and assemblage of different classess suggest the dominance of coarse sediments in boulder conglomerate (Folk 1957). The critical analysis of stattistical parameters show the Kurtosis value between of order of $0.90 \varnothing-1.20 \varnothing$, except in the area around where the sedimentation is affected by subsequent mixing of sediments brought by the rejuvenated stream of oscillating energy condition system in the closing phase of sedimentation. It seems that sediments were transported and deposited in the high dynomics condition. The platform of sedimentation display unstability as witnessed by configuration of sediment load and grain morphology of quartz garain and other associated minerals Khan (1914) \& Khan etal (1916). Inspite of strong variation in vales of kurtosis in the valley there is tendency in increase in kurtosis value in decreasing antiquity of sediment sequence.

\section{Fluvial Deposit:-}

\section{(Sediments of Paleo-domain of Narmada):-}

Mean Size (MZ):-

The average mean size (MZ) of sediments of terraces sediment NT1 to NT3 is $1.750 \emptyset$ (medium sand), $2.398 \varnothing$ (fine sand) and NT3 $3.422 \varnothing$ (very fine silt and clay), it varies from $0.755 \varnothing$ to $3.20 \varnothing, 0.255 \emptyset$ to $0.355 \varnothing$ and $0.330 \emptyset$ to $0.375 \varnothing$, i.e. the sediments of these terraces predominantly consist of very coarse to fine silt and clay.The mean size inspite of variation in NT1 to NT3 decreases in increasing antiquity in the valley and exhibits distinct upward fining sequence, which is typical fluviatile environment of paleo-domain of Narmada. 
The relative average and range values of mean size of sediments of NT1 depict the predominance of finer clastics in younger terrace sediment of paleodomain of Narmada. It perhaps indicates the reworking of sediments from the older quaternary deposits in the valley. The NT2 and NT3 exhibit sharp contrast in the mean size with the sediments of NT1. The NT3 displays distinct variation in mean size, suggesting that the sediments were brought and deposited by palaeo-domain of Narmada under uniform and constant energy conditions during sedimentation.

The statistical analysis of plots average and relative mean size of sediments and over all size distribution indicate persistent breaks in the coloumn of sediments of paleodomain in Narmada at four stages of sedimentation during Quaternary time which is represented by Sohagpur, Shahganj, and Hoshangabad and Janwasa formation in Narmada Valley.

\section{Inclusive Graphic standard Deviation ( $\delta$ ):-}

It is the measure of sorting which reflects the consistency in the energy level of depositing medium. The average value of the sediments of NT1 to NT3 is $1.250 \varnothing$ (poorly sorted), $1.596 \varnothing$ (poorly sorted) and $1.699 \varnothing$ (poorly sorted), $0.282 \varnothing$ (very poorly sorted ) and it varies from $0.195 \varnothing$ to $0.350 \varnothing, 0.156 \varnothing$ to $1.960 \varnothing, 1.450 \varnothing$ to $2.055 \varnothing$ and $0.530 \varnothing$ to $0.955 \emptyset$ and $0.335 \varnothing$ to $2.25 \varnothing$ respectively. It indicates the sediments exhibit the improvement in sorting in decreasing antiquity towards younger terrace and inversely related with the mean size. The break in standard deviation depicts the four stages of sedimentation in Narmada.

\section{Inclusive Graphic Skewness (SKI):-}

It denotes the symmetry of grain size frequency distribution. The symmetrical curves passes zero value, with the excess fine material show positive values and those with excess coarse material have negative values. The average (SKI) for NT1, NT2 and NT3 -0.155Ø ( Negative skewed ), -0.116Ø ( Negative skewed ), -6.196Ø ( Negative skewed ) and $2.38 \varnothing$ ( Very negative skewed ), it varies from $-0.125 \varnothing$ to $2.96 \varnothing$ ( negative to positive skewed ), $0.390 \varnothing$ to $0.135 \varnothing$ ( Very negative to positive skewed ) and $0.380 \varnothing$ to $1.29 \varnothing$ ( Very negative to positive skewed ) and $0.366 \varnothing$ to $0.133 \varnothing$ (very negative to positive skewed), $-0.335 \varnothing$ to $2.25 \varnothing$ (very negative skewed to positive skewed) respectively. The sediment of NT1 is positive skewed, whereas of NT2, NT3, It indicates that the sediments of, NT2, NT3 were deposited in the environments of high energy condition where as NT1 under low energy condition. The average and relative values of skewness suggest high load carrying capacity of channel system of paleo-domain of Narmada in the initial stages of sedimentation which was constantly declined towards later phase and stream was not capable to transport the sediment load significantly. The sediments of NT1 appear to have been mostly reworked and derived from the deposits of older terraces towards the late history of sedimentation.

\section{Graphic Kurtosis (KG):-}

It denotes peakedness of the curves of kurtosis (KG) (Platykurtic) points to a broad peak, while high value of KG (leprokurtic) denotes pronounced peak in the centre. The value of kurtosis of river terraces of Narmada is highly variable. The average value of NT1 is $1.646 \varnothing$ (leptokurtic), NT2 1.415Ø leptokurtic, NT3 is $1.120 \varnothing$ (Mesokurtic). The relative range value of NT1 is $1.520 \varnothing$ to $1.990 \varnothing$ (very leptokurtic), NT2 is $0.820 \varnothing$ to $2.480 \varnothing$ (platykurtic to very platykurtic) NT $0.679 \varnothing$ to $1.429 \varnothing$ (playkurtic to leptokurtic). The average value $1.326 \varnothing$ suggest strong variation in the energy condition of Narmada river and a more intensive sorting of central part of size distribution curve than the tail. Inspite of strong variation in kurtosis value there is constant and steady decrease in skewness value in increasing antiquity of terraces in Narmada valley. 


\section{Plate no.1:-}

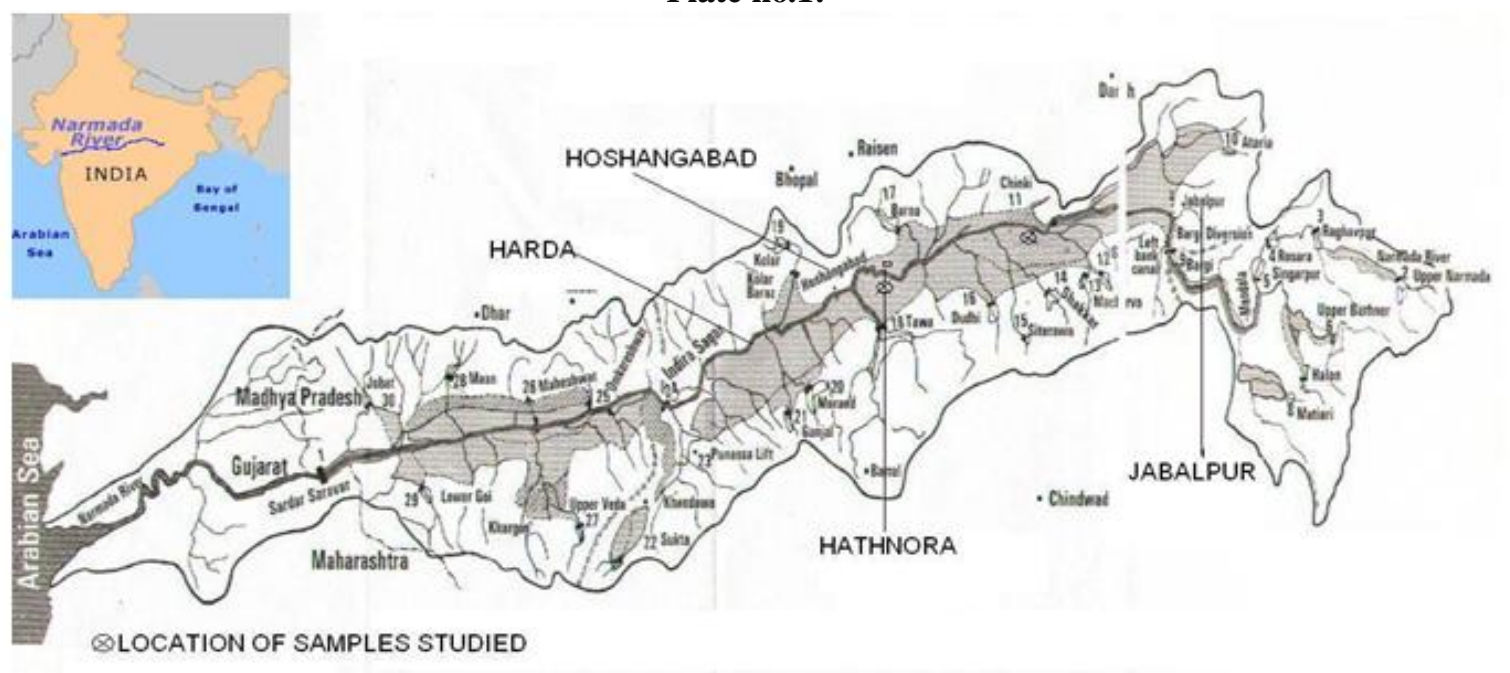

Plate no.2:-

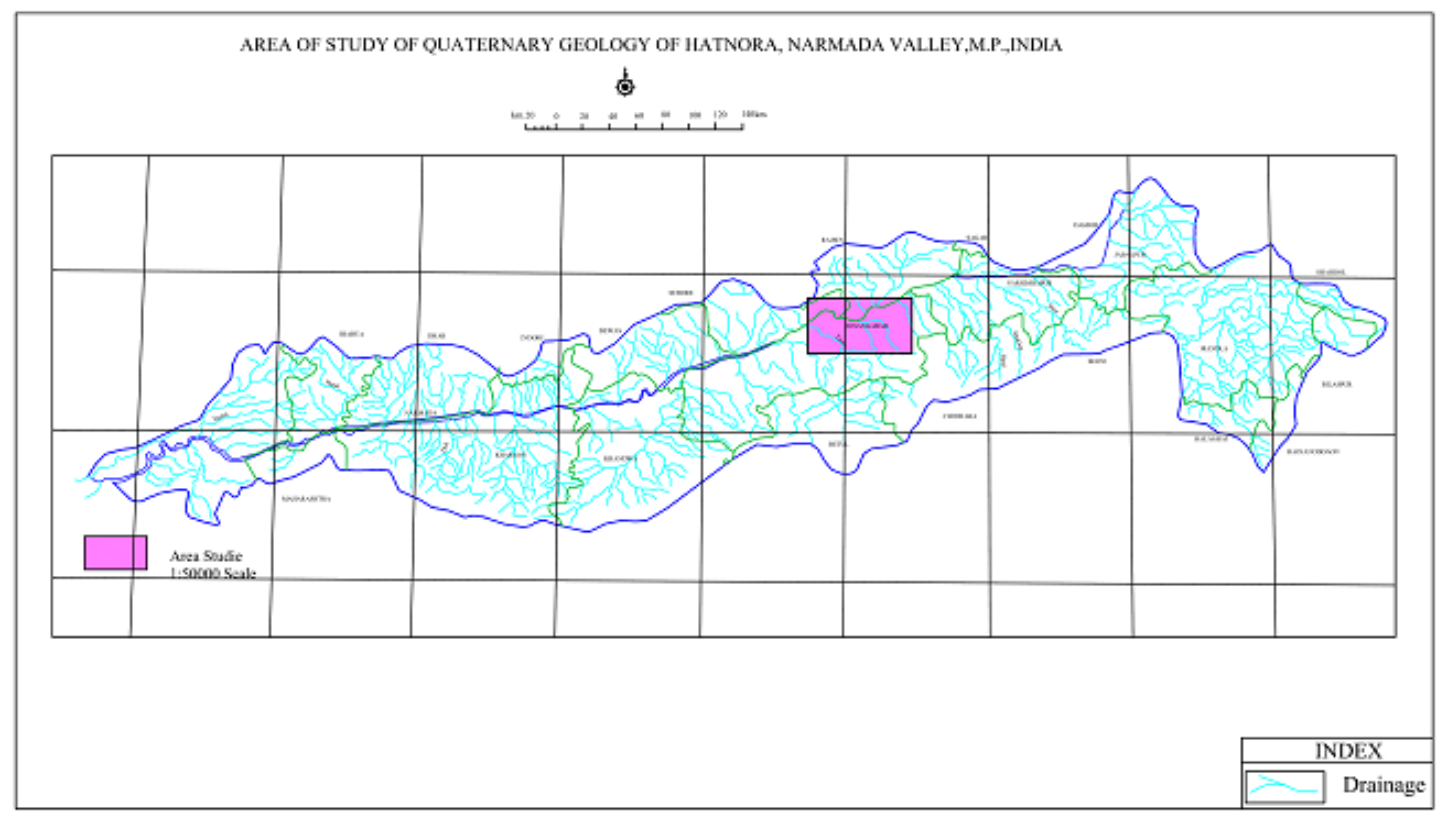


Plate no.3:-

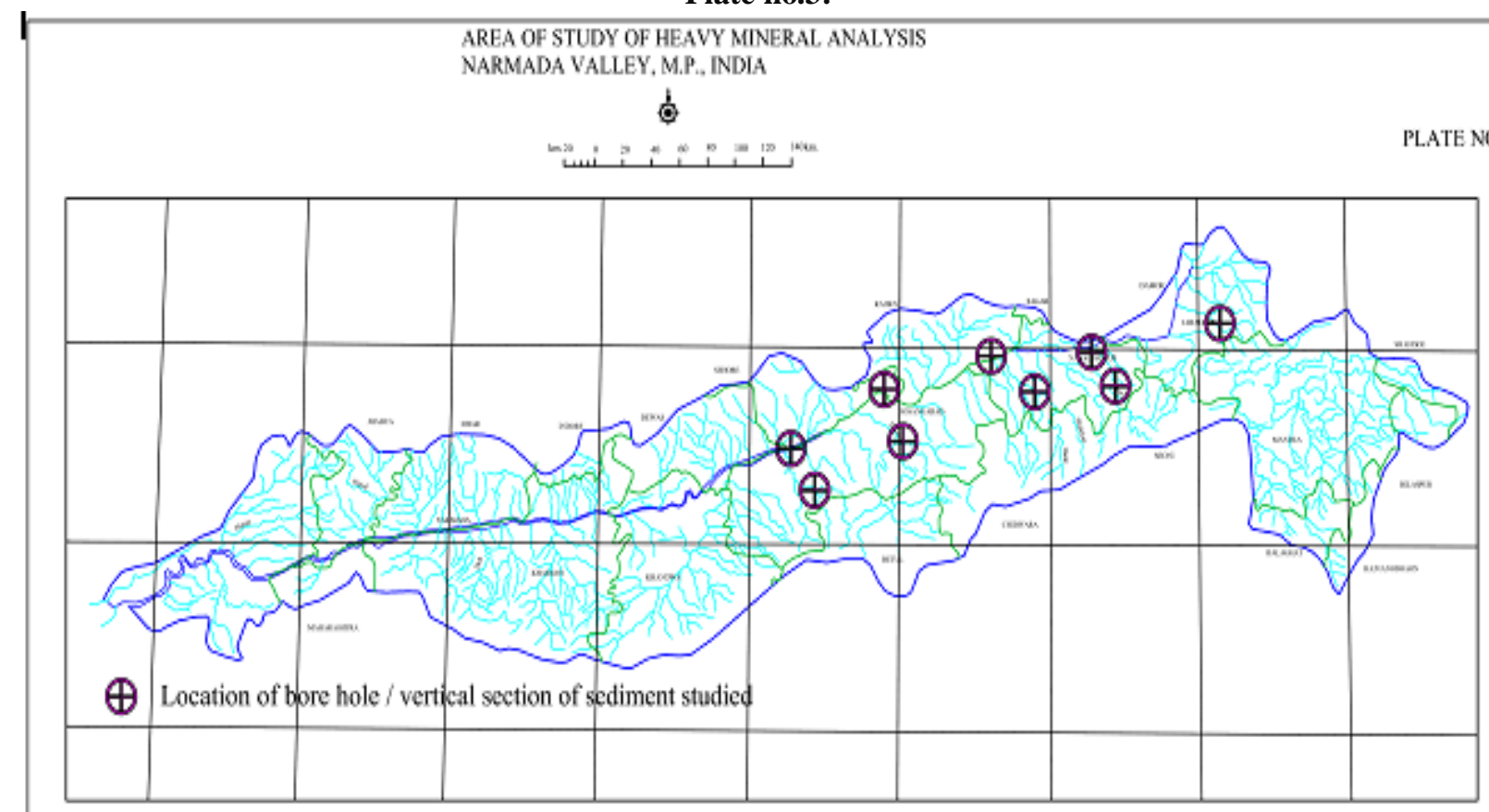

\section{Plate No.4}

SEDIMENTOLOGICAL LOG IN INCREASING ANTIQUITY \& VERTICAL VARIATION OF STATISICAL PARAMETERS OF QUATERNARY DEPOSITS OF GLACIAL, FLUVIO-GLACIAL AND FLUVIAL. DOMAIN OF NARMADA VALLEY M.P. INDIA.

HATHNORA SECTION_I

(22 ' $\left.52^{\prime \prime} \mathrm{N} ; 77^{\circ} 52^{\prime \prime} \mathrm{E}\right)$

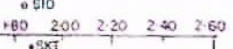

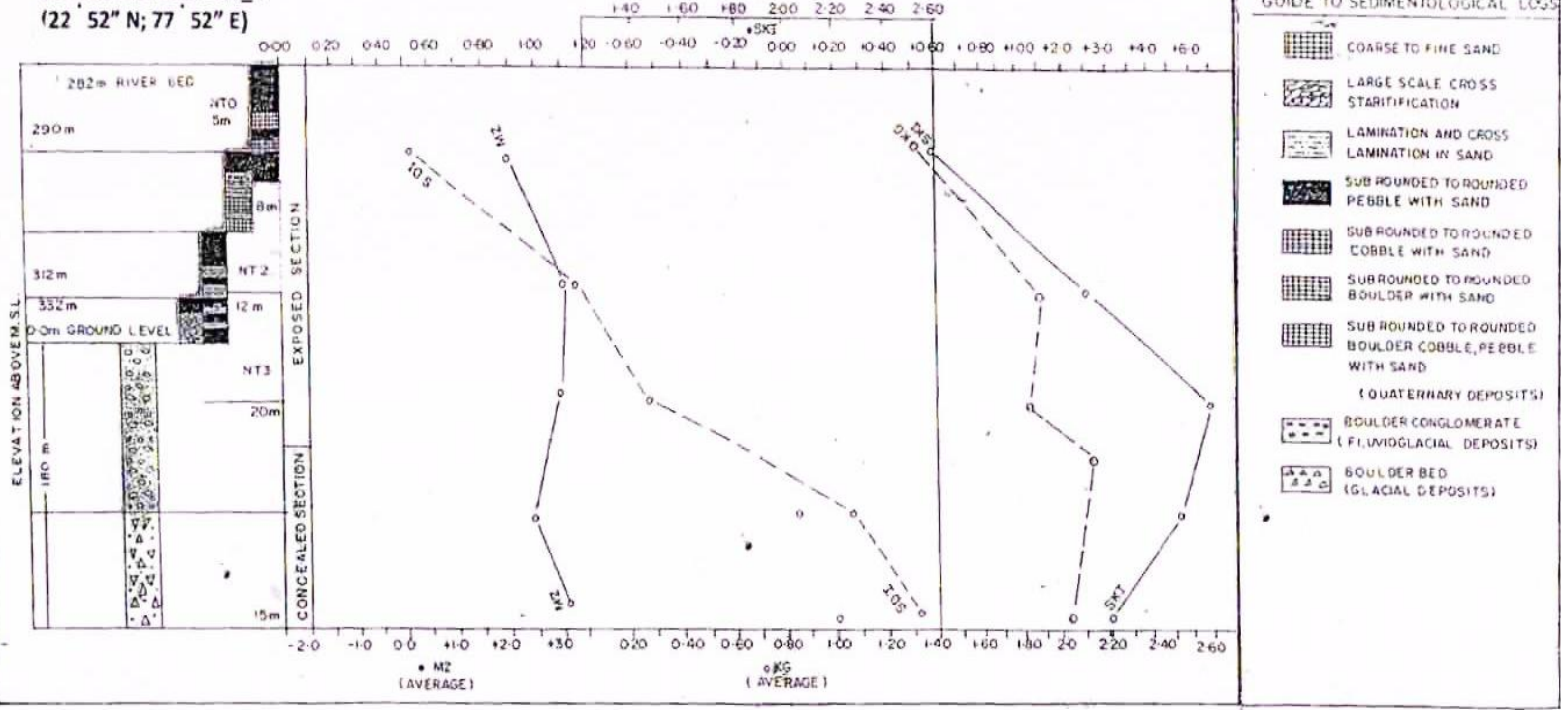

Plate No.5 


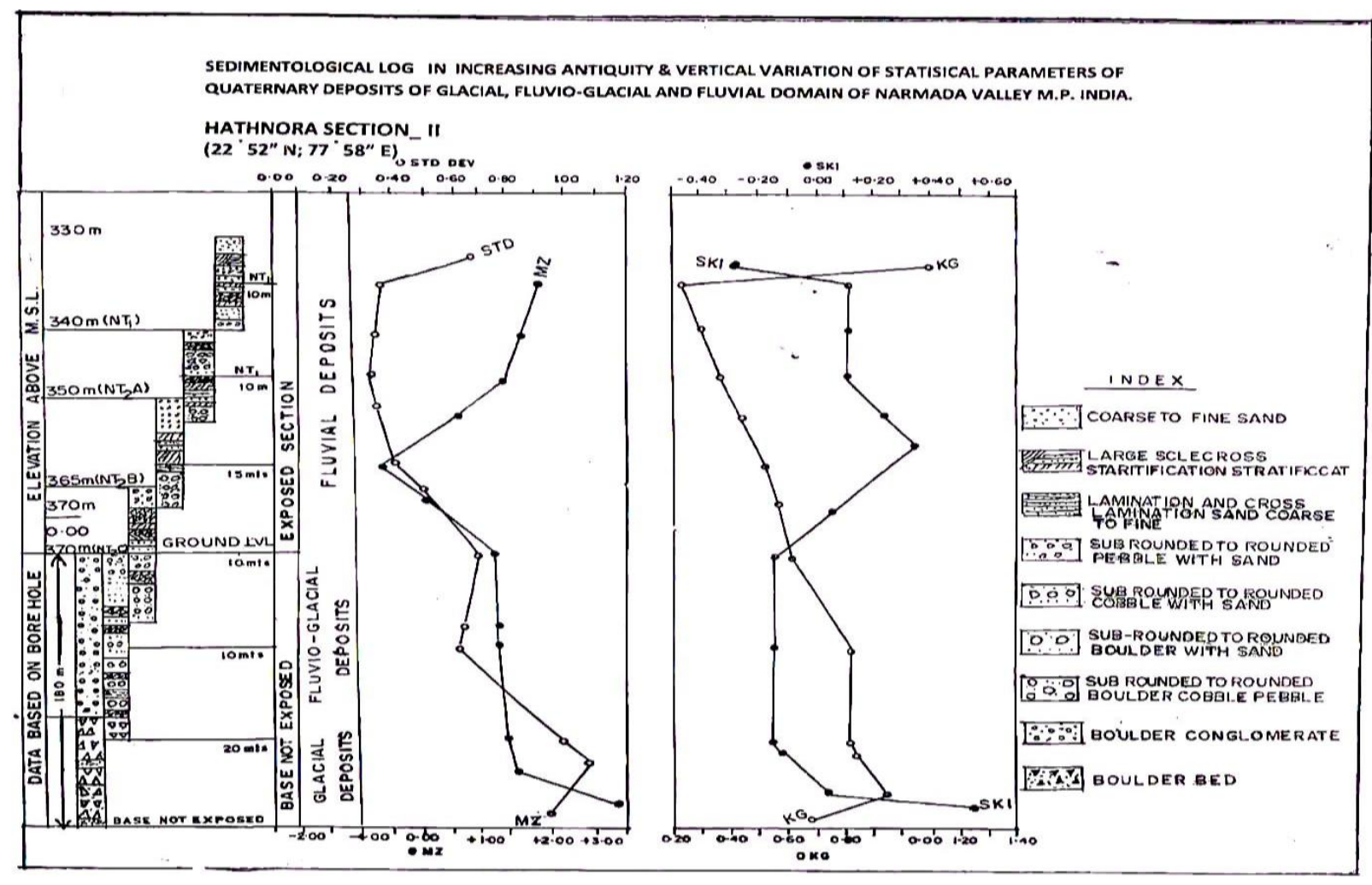

Plate No.6

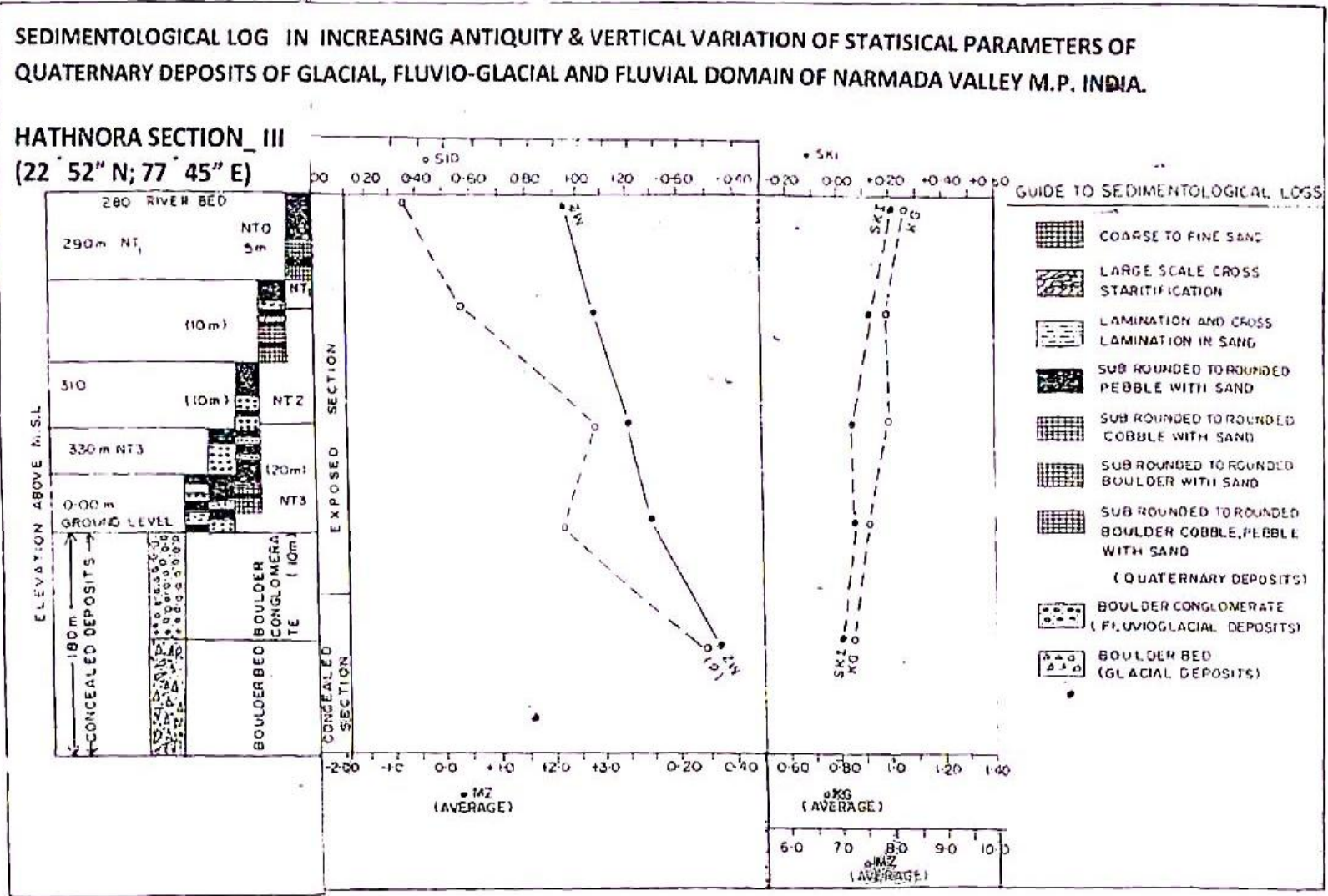


Plate No.7

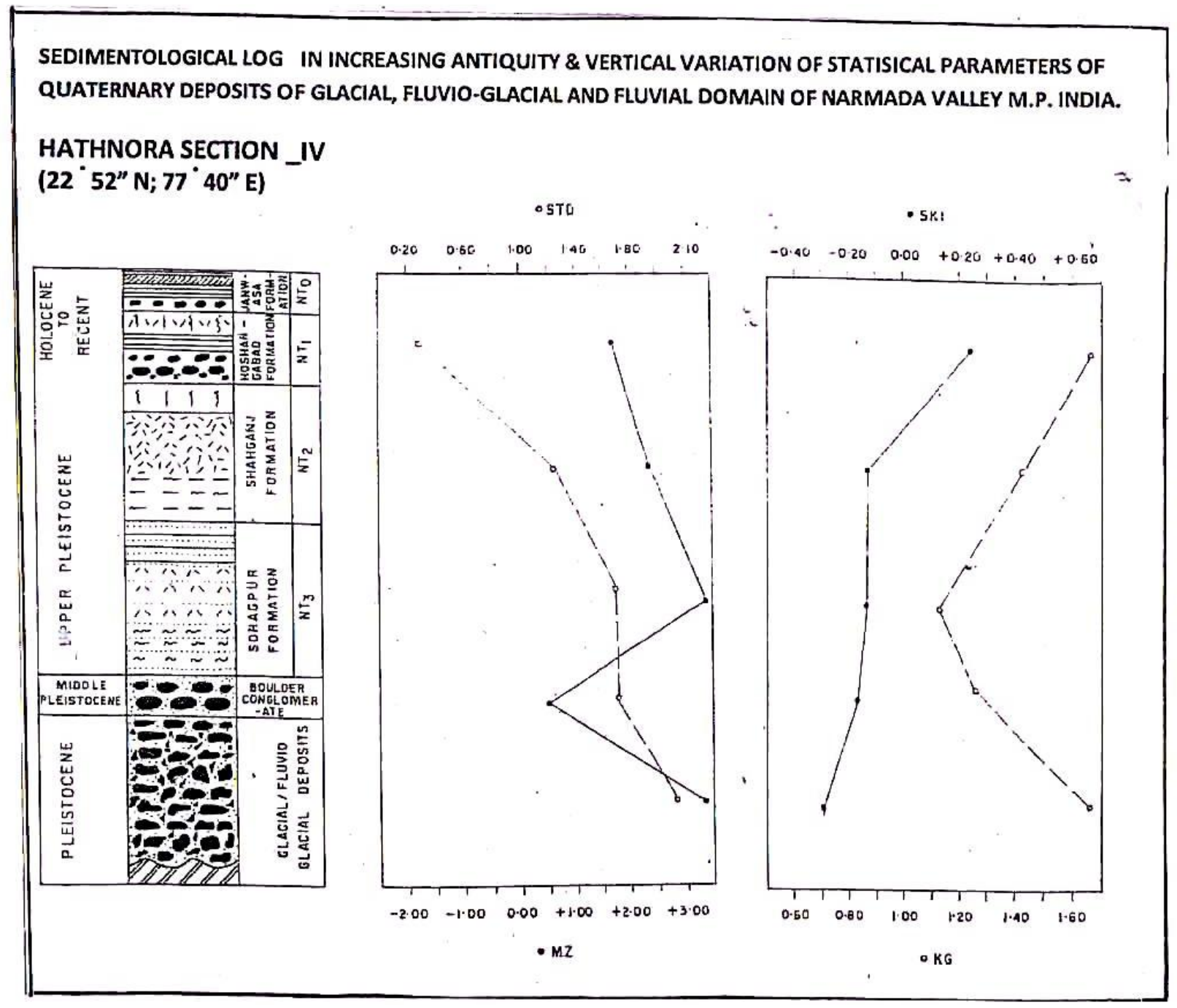

\section{Summary and Conclusion:-}

The Homonid locality Hathnora is located on the right bank of Narmada in Central sector in sehore district M.P. India from where Sonakia (1984) recovered human kull of Homo erectus from boulder conglomerate. The exposed section of Quaternary deposits is about $18 \mathrm{~m}$ and boulder conglomerate is exposed at the base of river section. In the vicinity quaternary deposits are confined in trough like basin, the boulder conglomerate is partly exposed and concealled under overlying younger deposits of paleo domain of Narmada ( NT1 to NT3). The boulder conglomerate is exposed only within the meandring loops of river due to lateral cutting. It is under liyan by boulder bed as intersected in drilling logs of different area in vicinity at an average depth of about $180 \mathrm{~m}$. The Narmada in this segment embodies the quaternary landscape with stepped sequence of Narmada terraces (NT1 to NT3) which comprised of sediments of paleodomain of Narmada resting over Boulder conglomerate in Quaternary coloumn. The Boulder conglomerate is persistent horizon and represent distinct fluvio-glacial phase of sedimentation. It is underlian by Boulder bed which is concealed in the valley.The Quaternary landscape on surface embodies the imprints of tectonic which indicates sedimentation was controlled by mechanics of SONATA LINEAMENT ZONE.

The Quaternary deposits of Narmada valley represent the thickest deposits in central India which were deposited in faulted and sinking platform of rift trench which is undisclosed and unrevealed. The work so far carried out is restricted to quatenary deposits of exposed section of $18 \mathrm{~m}$ only, as such no work has been done on concealed strata of quaternary deposits their source of sediment mode of transportation deposition tectonic and environment to conceive the model of quaternary sedimentation. In absence of information and data of concealed deposits of Narmada rift valley has restricted the systematic search of human remains with precise strata in synchronization of 
mechanics of tectonics and sedimentation. The records of search of human skull and its remains revealed that attemts were mostly random and confined to hominid locality Hathnora and around from where skull of Homo erectus was reported by Sonakia (1984), as such there after no further significant addition to the Paleontology and human remains in specific and its evolution. The present studies on various aspects of sedimentology of exposed section and bore hole logs across the vertical column of about $180 \mathrm{~m}$ in synchronisation of tectonisam and environment of sedimentation in vertical chronology is attempted which may provide clues and may assist in understanding the modal of quarternary deposits in Narmada valley in search of human skull and its remains.

In Hominid locality Hathnora in Section I to IV, 280 sediment samples were collect from exposed section and bore hole logs across the vertical column of about $180 \mathrm{~m}$. The statistical parameters viz MZ, STD, SKI, and KG of samples were computed from Quaternary deposits. The synchronized study of these parameters revealed that the quaternary blanket consists of sediments of three domain viz glacial, fluvio-glacial and fluvial representing Boulder bed, Boulder conglomerate and Fluvial terraces (NT1 to NT3), which were deposited in linear trench from Pleistocene to Upper Pleistocene time in increasing antiquity.

The Boulder bed consist of very coarse to fine sand silty and clay, average mean size (MZ) of sediments is $2.50 \emptyset$ (Find sand) where as it ranges from $-0.87 \varnothing$ to $3.45 \varnothing$ i.e the sediments consist of coarse to fine sand with silt and clay. The depth of Boulder bed is about $80 \mathrm{~m}$. The (MZ) of these sediments exhibit heterogeneous association and show significant variation from bottom to top in increasing antiquity and stratigraphic column. The erratic behavior of size matrix and sudden rise in mean size is conspicuous features of these deposits.It comprised of sediment which are poorly to very poorly sorted. The vaerage standard deviation is (ð) is $2.35 \varnothing$ (very poorly sorted), it varies from 1.42. $\varnothing$ to $3.875 \varnothing$ i.e. (from base to $80 \mathrm{~m}$ ) the sediments are poorly sorted to extremely poorly sorted. The majority of the sample shows the range of standard deviation of order ranging from $2.00 \emptyset$ to $3.355 \emptyset$. Among these $60 \%$ of sample show poor sorting, $20 \%$ very poor sorting and $20 \%$ extremely poor sorting. The sediments show no significant improvement in sorting in sediments column between 00.00 to $85.00 \mathrm{~m}$ from base below the surface. The variation in sorting appears to have been related with mean size, which is greatly affected by lateral mixing of sediments in valley at various points, improvement in sorting registered in the upper sequence byond $110.00 \mathrm{~m}$ with variation. These sediments are negative skewed to very positive skewed and of anisotropic nature. The average skewness is - $00258 \varnothing$ (very negative skewed) (from base to $80.00 \mathrm{~m}$ ). It ranges from $-0.425 \varnothing$ to $02.20 \varnothing$, which is interpretated that the sediments are very negative to positive skewed, $20 \%$ samples symmetrical $15 \%$ positive skewed $45 \%$ negative skewed $15 \%$ nearly symmetrical $15 \%$ positive skewed and $20 \%$ very positive skewed. The $55 \%$ samples in middle column of Quaternary strata between base to $55 \mathrm{~m}$ below the surface are coarse skewed and $45 \%$ fine skewed. The sediments exhibit erratic values of skewness in sediments column between bases to $30 \mathrm{~m}$ at depth below the surface. The sediments are assorted and as a whole show strong variation in departure towards coarseness as well as with fineness. The departure from symmetry appears to be related with deviation of mean size. In general the asymmetry passes from middle to upper segment are coarse skewed to fine skewed, which suggest constant variation in energy condition of the transporting system during sedimentation. Petijhon, (1957)

The sediments are mesokurtic to very leptokurt in natur.The average value of Kurtosis of (KG) is $0.98 \varnothing$ (Mesokurtic). It ranges from 0.60 to $1.85 \emptyset$ (very platykurtic to very leptokurtic). The $6 \%$ samples are very leptokurtic, $50 \%$ mesokurtic, $21 \%$ leptokurtic, $23 \%$ are platykurtic. The $68 \%$ of samples in the lower strata below $150 \mathrm{~m}$ at depth is mesokurtic where as in the middle segment of Quaternary strata between $75-150 \mathrm{~m} 40 \%$ are meokurtic where as in the upper sediments column between 30 to $120 \mathrm{~m}$ at depth below the surface $26 \%$ sample are meokurtic.The relative values of kurtosis in relation to the depth and configuration of the basin suggests non static and oscillating platform of sedimentation in central part of valley related to the change of climate and consequential change in the energy condition of the system.

The binary plot of coefficient of sorting v/s skewness indicates that (a) the fluvio glacial deposit sediments have very wide and open area of operation which is practically boundless and all inclusive and that the plots of sediments of fluvial deposits concentrate and cluster with in the short range of standard deviation and -0.40 to to- 0.98 and skewness -0.20 to -0.40 which indicate that sediments are well sorted and subjected to the nonstatic environment of stream kinetics with a fair degree of accuracy a straight line of coefficient of sorting of value 1.20 has seprated fluvial sediments from $85.25 \%$ sediments of glacial domain. The instant incursion of glacial sediments in the domain of fluvial sediments as depicted may be due to partial fluvial behavior of glaciers to wards the dying phase.In the binary plot of coefficient of sorting v/s mean diameter indicates that about 80 percent of -glacial sediments are wide spread and in close proximity of fluvioglacial plots, where as the plots of fluvial sediments concentrate closely and confined with mean size +1.00 and sorting range 0.40 to 1.20 . The rest however show the 
boundless erratic behaviors. The sediments plots are widely spread and do display trend in oriented trend which separates mainly the fluvial sediments from sediments of other domain in the area of study

The Boulder conglomerate contain very coarse to fine sand with rock gravel. The average mean size of sediments of is $1.032 \varnothing$ (medium sand) (170 to $240 \mathrm{~m}$ ). It varies from $-2.53 \varnothing$ to $3.12 \varnothing$ i.e. the sediments consist of very coarse to very fine sand. The size distribution of these deposits in the study area is extremely irregular and erratic. Out of 50 samples $10 \%$ of sample show range of mean size of order of $0.75 \varnothing-0.50 \varnothing, 0.25 \varnothing$ to $0.75 \varnothing, 25 \%, 0.75 \varnothing$ to $1.75 \varnothing,, 1.75 \varnothing$ to $2.50 \varnothing$ and $19 \%$ beyond $2.50 \varnothing$ The sediments close to the under lying Boulder bed the down sequence ranges $0.75 \varnothing$ to $0.50 \varnothing$ i.e. coarse to very coarse sand which constantly show decrease in mean size. The sediments in the vicinity of Hathnora along about $20 \mathrm{~m}$ below the surface show range of order of $1.25 \varnothing$ to $2.75 \varnothing$ with local variation. The sudden rise in mean size of Narmada show values of order $0.50 \varnothing$ to $0.15 \varnothing$ which indicates the intensive mixing of sediments brought from the flash stream resulting from the glacier front at different point in the valley. The sudden anomalous variation in mean size is attributed to the adding of a large bulk of sediments by streams perhaps brought by sub-glacier resulted due to melting of glacial due to climatic changes

The sediments are moderatly sorted to well sorted sediments the average value of standard deviation (ð) of sediments of boulder conglomerate is 1.563 (extremely poorly sorted) where as it varies from 0.95 to $2.50 \emptyset$ i.e. the sediments are poorly sorted to very poorly sorted (170 to $240 \mathrm{~m}$ ). The statistical analysis of 50 samples indicate that $8 \%$ sample are moderately sorted, $10 \%$ poorly sorted and $82 \%$ are very poorly sorted. The sediments near the source are conspicuously exhibit poor sorting and show significant improvement upward sequence with local variation. As a whole the sediments are poorly sorted to very poorly sorted and heterogonous in nature sand are typically of fluvio glacial origin.

The sediments which show variable skewness (SKI) values. The average of skewness is $0.078 \varnothing$ i.e. the sediments are fine skewed ( 170 to $240 \mathrm{~m}$ ), where as it varies from $-0.48+0.97 \varnothing$ i.e. the sediments are skewed very negative to skewed very positive. Out of 50 samples $66 \%$ are skewed positively, $14 \%$ skewed positive and $20 \%$ are skewed very negative. The relative percentage of samples and their valuves suggests the heterogeneous association of the sediments ranging from fine sand to gravel size. The skewness in general increase with increasing antiquity with occasional variation. It is perhaps due to repeated reworking of the sediments by stream resulting from the glacier. The kurtosis (KG) is 1.316 (leptokurtic) from base to $80 \mathrm{~m}$. It ranges from $476 \varnothing$ to $1.52 \varnothing$ platykurtic to very leptokurtic among these $75 \%$ of the sample fall in very platykurtic class Mesokurtic $45 \%$ leptokurtic. The assemblages of these classes of kurtosis suggest the dominance of coarse sediments (Folk 1957). Most of the samples show the kurtosis value between $0.90-1.20$ except in the area around Hathnora. It seems that sediments were transported and deposited in the oscillating kinetic sedimentation.

The binary plot of skewness $\mathrm{v} / \mathrm{s}$ means diameter indicates that the fluvio glacial sediments cannot be limited to a particular domain due to erratic sedimentary processes and erratic and violent dynamic of transporting system. However, the prefential trend of cluster has been found which is most affective used in concentrating and separating $97 \%$ percent fluvio glacial sediments form sediments of glacial origin. The affectivity of plot kurtosis v/s mean size may be used as tool in delineating a flexible boundary between the glacial and fluvio glacial sediments. The cluster trend is organised and prefential it separates $87 \%$ of the fluvial sediment from the $94 \%$ of the fluvio-glacial.

The sediments of paleodomain of Narmada exhibit varaiable valves of mean size viz NT-1 average value is $1.730 \varnothing$ (fine sand) where as it varies from 3.200 to $6.745 \varnothing$ (medium to fine sand). The vaerage value of mean size of terrace deposits NT-2 (NT-2A, NT-2B, NT-2C) is $2.390 \varnothing$ (medium sand) and it ranges between -0.425 to 2.296 (very coarse sand to fine sand). The average value of mean size of terrace NT-3 is $3.422 \varnothing$ (medium sand) and ranges from 0.255 to $0.355 \varnothing$ (medium sand to very fine sand). The average and relative values of mean size in this domain of sediments revealed that the sediments of older terraces NT-2(NT-2A, NT-2B, NT-2C) and NT-3 consist of very coarse to very fine sand where as younger terrace NT-1 (NT-2A, NT-2B) and NT2 predominantly medium to fine sand, except with very little variation, it progressively decreased in decreasing antiquity of terraces which appears to be related reworking and steady decrease in load carrying capacity of channel towards the latter stages of sedimentation. The variation in mean size suggests the fluctuation in energy condition of channel system is related with unstability of valley floor and neotectonic mechanics of the area.

The average value of standard deviation for the sediments of NT-1 is $0.275 \varnothing$ (very well sorted) and it ranges from 0.195 to $0.350 \varnothing$ (well sorted to very well sorted). Average value of sorting for the sediments of terrace NT-2 (NT- 
2A, NT-2B, NT-2C) is $1.250 \varnothing$ (moderately sorted) and it ranges from 0.156 to $1.960 \varnothing$ (well sorted to very well sorted). Average value for the sediments of terrace NT3 is 0.376 (well sorted) and it ranges from 1.450 to $2.050 \varnothing$ (well sorted to very well sorted). The average and relative range values of standard deviation indicate that the sediments of older terraces NT31.596 Ø it ranges $1.430 \varnothing$ to $2.052 \varnothing$ are moderately sorted to well sorted NT2 (NT2A, NT-2B, NT-2C) well sorted to very well sorted and NT1 well sorted to very well sorted and NT0 are very well sorted. The sediments show progressive improvement in sorting from older terraces to younger terraces appears to be related with the mean size and energy condition of the channel, which constantly decrease towards the later phases of sedimentation. The size distribution curve reveals more than one population of sediments whereas the probability plot reveal that the terraces NT-1 to NT3 average consist of 57\% and $43 \%$ traction and suspension 1cad respectively. The traction load decreases in decreasing antiquity of terraces in the valley.

The average value of skewness for terrace NT-1 is $0.213 \varnothing$ (positive skewed). It ranges from 0.125 to $0.296 \varnothing$ (very negative skewed to very positive skewed). Average value of skewness for terrace NT-2 (NT-2A, NT-2B, NT-2C) is $+-0.155 \varnothing$ (positive skewed), it ranges from -0.592 to 0.232 (very negative skewed to positive skewed). Average value for terrace NT-3 is +-0.116 (very positive skewed), it ranges from $0.380 \varnothing 0.129 \varnothing$ (very negative skewed to very positive skewed). The sediments of terrace NT-1 is strongly negative skewed where as the sediments NT2 to NT-3 are progressively positively skewed. The negative skewness is resultant of high energy condition whereas the positive skewness indicates low energy. The average and relative range values of skewness from NT-1 to NT-3 indicate the decrease in energy condition of channel towards the late history of sedimentation. The average value of Kurtosis for terrace NT-1 is $1.646 \varnothing$ (very platykurtic) it ranges from $1.520 \varnothing$ to $1.990 \varnothing$ (platykurtic). The average value for NT-2 (NT2-A, NT2-B, NT2-C) is $1.415 \varnothing$ (very platykurtic) and ranges from 0.263 to $0.539 \varnothing$ very platykurtic). The average value for terrace NT3 is $1.120 \varnothing$ (very platykurtic) and varies from 0.679 to $1.429 \varnothing$ (platykurtic to very platykurtic).The sediments of NT3 are platykurtic to very platykurtic and NT-1 to NT3 are very platykurtic in nature. The average value of Kurlosis decreases upwards which indicate a normal peakednes $\mathrm{s}$ of sediments as well strong concentration of grains around median diameter. The relatively lower value of NT-1 indicates that most of the sediments were derived from close proximity and nearest provenances.

The synchronized study of these parameters revealed that the quaternary deposits consists of sediments of three domain viz glacial, fluvio-glacial and fluvial representing Boulder bed, Boulder conglomerate and Fluvial terrace deposits of paleodomain of Narmada (NT1 to NT3), which were deposited from Pleistocene to Upper Pleistocene time. The study of various parameters their binary relation, their concentration of plots cluster trends and patterns revealed three breaks in vertical column $120 \mathrm{~m}, 210 \mathrm{~m}$ and $280 \mathrm{~m}$ i.e glacial, fluvio-glacial and fluvial phases of sedimentation in increasing antiquity in Narmada valley in Central India .

\section{References:-}

1. Acharya, S.K. and Basu, P.K. (1993): Toba ash on the Indian subcontinent and its implication for correlation of late Pleistocene alluvium.Quaternary Research, No.-14. Pp10-14.

2. Folk R.L. and Ward W.C.1957 "Brajors River Bar - A study in the of grain size parameters significance J.Sed. Pet., 27, 3-27

3. Khan A.A. \&Balchandran,V (1974-75) Records Volume109 of Gelogical survey Of India partI,pp.59

4. Khan A.A. 1984 Geology of Geomorphological studies in parts of Narmada Basin, Sehore Dist. Of M.P. GeolSurv. Of India Progress Report (Unpublished).

5. Khan, A.A. \& Banerjee, S.N. (1984) Geology and Geomorphological studies in the parts of Narmada Basin, Sehore district of M.P. Un Pub. Report. Geol. Surv. India.

6. Khan, A.A. (1984) Geological and Geomorphological studies around Tapti-Vagher confluence district Jalgaon, Maharashtra. Geol, Surv. India Rec. V.113 pt 6 pp 99-109

7. Khan A.A. and Bajerjee, S.N. 1985: Geomorphological and geological studies of Quaternary sediments in collaboration with project Crumansonata in parts of the Narmada basin, Sehore, Dewas and Hoshangabad districts unpublished Geol. Surv. Ind. Progress Report.

8. Khan, A.A. (1990) Geomorphology of Narmada Valley Of Jabalpur_ Handia Section Unpublished G.S.I Note.

9. Khan, A.A., and Rahate, D.N (1990-91 \& 1991-92) Geological and Geomorphological studies in parts of Narmada Basin) parts Hoshangabad and Narshingpur district, M.P. Geol. Surv. Of India Unpublished Progress Report.

10. Khan, A.A.( 1991).Geological studies of Harda - Barwaha basin in parts of Dewas, Sehore, Hoshangabad and Khandwa districts with the Aid of Satellite imagery and Remote Sensing Techniques, Geol. Surv. Ind, Rec. Vol; 126 pt-6 
11. Khan, A.A, Rahate, D.N. (1991) Volcanic Ash from Quaternary deposits of Narmada Valley Central India. Proceed, of $78^{\text {th }}$ session of Indian Sci. Cong. Association. (Abstract) pt. III pp 28-29

12. Khan, A. A, Rahate, D.N, Fahim, M \& Banerjee, S.N.( 1991 ) Evaluation of Quaternary terrace of lower Narmada valley, Districts Sehore and Hoshangabad, Madhya Pradesh

13. Khan, A.A., Rahate, D.N; Shah; (1991) M.R. and Fahim; M. volcanic Ash from Quaternary deposits of Narmada valley central India. Indian science Congress 1991

14. Khan, A., \&Sonakia, A. (1992). Quaternary deposits of Narmada with special reference to the hominid fossil. Journal of the Geological Society of India, 39, 147-154.

15. Khan, A.A, Rahate, D.N, FAHIM, M. and Banarjee,S.N ( 1992) Evaluation of Geology and Geomorphology in Central Narmada Valley ( Districts Sehore and Hoshangabad, Madhya Pradesh ) Scientific Publishers, Jodhpur.

16. Khan, A.A; Rahate D.N, Fahim, M. and Banarjee, S.N. (1992): Evaluation of Geology and Geomorphology in Central Narmada Valley (Districts Sehore and Hoshangabad, Madhya Pradesh) Scientific Publishers, Jodhpur

17. Khan A.A. 1994 Geological and Geomorphological studies around Tapti-Vagher confluence district JaloaonMaharastra, Geol. Surv. Of India, Rev. Vol. 113 pt. 6 pp 99 - 109.

18. Khan A.A. \& Maria Aziz (2012)"Homo erectus On Unified Quaternary Platform in India and China a Correlation \& Sequential Analysis". Status Published Research Scapes International Journal Vol I, Issue IV October -December 2012. (ISSN: 2277-7792)

19. Khan. A.A. \& Aziz, Maria (2012) "Homo Erectus \& Homo Sapiens In Spectrum Of Volcanic Ecology, Narmada Valley (M.P) India"Status Published Research Scapes International Multidisciplinary Journal VolI, Issue III July-September 2012

20. Khan, A.A. \& Aziz; Maria (2013) Homo Erectus\& Homo Sapien in Spectrum of Volcanic Ecology, Narmada valley (M.P.) India Research scapes vol. i issue -4 pp-161 -178.

21. Khan A.A; \& Joshi O.P. ( 2014) Geology Lithostratigraphy And Correlation of Basaltic Lava Flows of Parts of Western Madhay Pradesh With Special Reference To Megacryst Bearing Horizons And Geotechnical Aspects For Heavy Engineerging Structures.

22. Khan, A.A \& Aziz, Maria (2014-15) Tectonics Evolution, Quaternary Sedimentation, And The Paleoanthropological Record InThe Narmada Rift System (m.p.) Central India Khan*, A.A. Aziz, Maria International Journal for Research and Technological Sciences Vol. 1, Issue 1 (2014) 91-93 ISSN -2349-0667.

23. Khan A.A. \& Aziz, Maria (2015) Quaternary Tectonics \& Sedimentation in Narmada Rift Valley, With Special Reference to Garudeshwar and Bharuch Section Gujarat State India, ISSN 2320-5407 International Journal of Advanced Research (2015), Volume 3, Issue 3, 430-457 430 Journal homepage: http://www. journalijar. com

24. Khan, A.A. \& Aziz; Maria (2014-2015). Quaternary volcanic Eruption Toba Ash fall its impact on Environment of late Pleistocene Hominines in Indian subcontinent with Special Reference to Narmada Valley. International journal of Research in Technological sciences vol.1, Issue 2 \& Vol-2 issue-1 July -January 2014 January-June 2015 PP1-18 (ISSN-2349-0667).

25. Khan, A.A. Aziz; Maria (2015) A critical analysis of statistical parameters of quaternary deposit of Hominid locality, Hathnora, Narmada valley, distirctsehore (M.P), India Jour. Of Agriculture, Foresty and Environment al Science Vol.IIssue.I July -Aug 2015 .I pp 17-29 ISSN 2454-2792

26. Khan A.A. \& Aziz, Maria (2016)Heavey Minerals assemblage of quaternary column of hominid locality Hathnora, Nnarmada valley district SehoreM.P India. ISSN 2320-5407 International Journal of Advanced Research (2016), Volume 4, Issue 7, 1748-1780 Journal homepage: http://www. journalijar. com.

27. Pascoe, E.H. 1973: A manual of geology of India and Burma, Vol. III, Govt. of India Publication

28. Petijhon, F.G. (1957) Sedimentry rocks $.2^{\text {nd }}$ edition Harper\& Brothers .New York p.718

29. Roy, A.K. 1971 Geology and Ground Water Resources of Narmada Valley Bult of GeolSurv. Of Ind Series B. Engineering Geology and Ground Water Geology.

30. Sonakia A. 1984 The Skull Cap of Early man and associated mammalian fauna from Narmada Valley alluvium Hoshangabad area. Madhya Pradesh, India Rec. GeolSurv. India Vol. 113, Pt. 6 pp 159-172.

31. Sankhyan, A. R. (1997b). A new human fossil find from the Central Narmada basin and its chronology. Current Science, 73, 1110-1111.

32. Khan A.A. \& Aziz, Maria (2016) Heavey Minerals assemblage of quaternary column of hominid locality Hathnora, Nnarmada valley district SehoreM.Pindia. ISSN 2320-5407 International Journal of Advanced Research (2016), Volume 4, Issue 7, 1748-1780 Journal homepage: http://www. journalijar. com. 